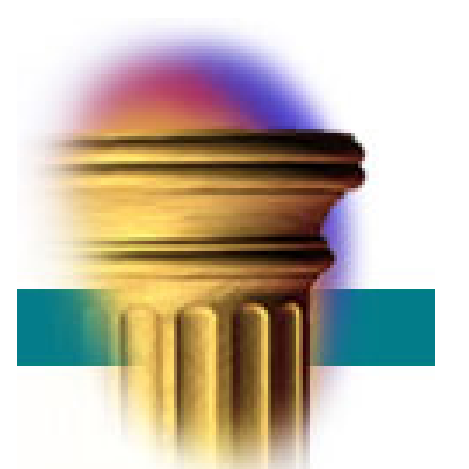

\title{
요 \\ Affordability, Financial Innovation, and the Start of the Housing Boom
}

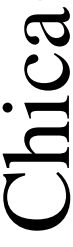

象

龺

U

范

番

๓

Jane K. Dokko, Benjamin J. Keys, and Lindsay E. Relihan

\author{
January, 2019
}

\section{WP 2019-01}

https://doi.org/10.21033/wp-2019-01

${ }^{*}$ Working papers are not edited, and all opinions and errors are the responsibility of the author(s). The views expressed do not necessarily reflect the views of the Federal Reserve Bank of Chicago or the Federal Reserve System. 


\title{
Affordability, Financial Innovation, and the Start of the Housing Boom*
}

\author{
Jane K. Dokko \\ Federal Reserve Bank \\ of Chicago
}

\author{
Benjamin J. Keys \\ The Wharton School \\ University of Pennsylvania \\ and NBER
}

\author{
Lindsay E. Relihan \\ London School \\ of Economics
}

January 2019

\begin{abstract}
At their peak in 2005, roughly 60 percent of all purchase mortgage loans originated in the United States contained at least one non-traditional feature. These features, which allowed borrowers easier access to credit through teaser interest rates, interest-only or negative amortization periods, and extended payment terms, have been the subject of much regulatory and popular criticism. In this paper, we construct a novel county-level dataset to analyze the relationship between rising house prices and non-traditional features of mortgage contracts. We apply a break-point methodology and find that in housing markets with breaks in the mid-2000s, a strong rise in the use of non-traditional mortgages preceded the start of the housing boom. Furthermore, their rise was coupled with declining denial rates and a shift from FHA to subprime mortgages. Our findings support the view that a change in mortgage contract availability and a shift toward subprime borrowers helped to fuel the rise of house prices during the last decade.
\end{abstract}

\footnotetext{
${ }^{*}$ We thank Neil Bhutta, Anthony DeFusco, Leonard Kiefer, Karen Pence, Amit Seru, Amir Sufi, and numerous participants at conferences and seminars for helpful comments and suggestions. Min Kim and Trevor Woolley provided excellent research assistance. Keys thanks the Research Sponsors of the Zell/Lurie Real Estate Center at Wharton for financial support. These views are those of the authors and do not reflect those of the Federal Reserve Bank of Chicago or the Federal Reserve System. Any remaining errors are our own. Contact: jane.dokko@chi.frb.org benkeys@ wharton.upenn.edu 1.relihan@1se.ac.uk
} 


\section{Introduction}

The dominance of the 30-year fixed rate mortgage is a defining feature of the United States housing market (Green and Wachter 2005). For a brief period in the mid-2000s, however, this dominance was challenged by the popularity of non-traditional (or "alternative") mortgage products that allowed borrowers easier access to credit through variable interest rates with teasers, extended payment terms, and interest only or negatively amortizing repayment schedules. In effect, borrowers could pay less than 30-year fully amortizing monthly payments for some period of time. As Figure 1 shows, the share of mortgages with at least one alternative financing feature grew sharply during the years of the most rapid house price appreciation. At their peak in 2005, about sixty percent of all purchase loans originated in the United States contained at least one alternative financing feature. Their coincidence with increasing house prices led many to conclude that they were used to speculate on the housing market and, thus, partly to blame for the boom. However, given that incomes rose little during that period, borrowers may have instead flocked to non-traditional mortgage products to maintain affordability in a time of increasing home prices (Mian and Sufi|2009) 11 Accordingly, it remains unclear whether their restriction would prevent future booms or rather hurt borrowers by restricting more affordable mortgage products.

In this paper, we explore the direction and magnitude of the relationship between rising house prices and non-traditional mortgage products using new data and methods. Much of the previous research treats the housing boom as a single, national event ${ }^{2}$ However, this view only provides information on the average trends in highly local, heterogeneous housing markets. In contrast, we use detailed data on over 60 million loans describing almost every possible feature of new originations to construct measures of the use of nontraditional mortgage products in each county and month from 1993 - 2007. We complement the originations data with house price indices for 1,163 counties and additional measures that shape local housing markets, such as economic fundamentals and credit supply. This rich cross-sectional and time-series variation across and within local housing markets allows us to observe changes that would be obscured in the aggregate.

In our empirical work, we implement a breakpoint randomization methodology to identify the start of local house price booms and systemically study the time-series relationship between the start of these

\footnotetext{
${ }^{1} \mathrm{~A}$ further concern, which we do not address, is the practice of product steering or predatory lending involving these nontraditional products during the housing boom (Agarwal et al. 2014a, 2016) .

${ }^{2}$ Three notable exceptions are Ferreira and Gyourko (2011), Charles et al. (2018), and DeFusco et al. (2018).
} 
booms and the use of non-traditional products $3^{3}$ This methodology is motivated by our stylized model of local mortgage markets, which illustrates the simultaneity between house prices and mortgage products and highlights which features of local markets are likely to change under shifts in expectations versus the cost of lending. Our approach is a departure from previous research on non-traditional mortgage products, which primarily focused on the optimal structure of non-traditional products (Campbell and Cocco 2003; ;iskorski and Tchistyi 2010, 2011), the features of borrowers who use them (Amromin et al.2018), or their theoretical ability to generate speculative booms (Barlevy and Fisher 2011).

To illustrate our breakpoint methodology, one notable example is the experience of Clark County, Nevada, where Las Vegas is located. The house price index for Clark County is shown in Figure 2 (a). Our methodology estimates that the Clark County housing boom began in February 2004. In the figure, there is a clear difference in both the house price path and rate of house price appreciation on either side of the estimated breakpoint. In Clark County, we find that the rapid adoption of non-traditional mortgage products began earlier than the estimated start of the local housing boom (shown in Figure 2(b)). More specifically, prior to the boom in the early 2000s, 20 percent of purchase mortgage contracts have an alternative feature; this share increases sharply beginning around mid-2003 so that by early 2004,60 percent of contracts have at least one feature. This example of Clark County provides an overview of our empirical approach and highlights how, in one market, non-traditional housing finance trends preceded the house price boom.

In our analysis of the relationship between house price booms and non-traditional mortgage products, we formalize this comparison, as well as separately analyze early- and late- booming markets, defined as counties with structural breaks in house price appreciation before and after the year 2000, respectively. This split-sample analysis is motivated by the financial liberalization and deepening of the secondary market after 2000 that allowed lenders to not only make more loans, but pass on the riskiest to third parties (Keys et al. 2010; Rajan et al. 2015). Furthermore, these early- and late-booming counties are concentrated in fundamentally different geographic areas. Many late markets, like Las Vegas and Phoenix, had a relatively elastic housing supply and no history of extreme housing cycles (Himmelberg et al. 2005; Sinai 2013 ). In contrast, booms before 2000 took place without these same financial conditions and, as Ferreira and Gyourko (2011) and DeFusco et al. (2018) also find, occurred in more urban, coastal markets, such as San

\footnotetext{
${ }^{3}$ Our methodology is based on the theory in Hansen (2000) and similar to that implemented by Ferreira and Gyourko (2011) and Charles et al. (2018).
} 
Francisco and Boston.

In markets with early housing booms (before 2000), we first establish that non-traditional mortgage products are unlikely contributors to the sharp increase in house prices at the start of a county-specific boom. In addition, for early-booming markets, we find little evidence of credit supply growth in the years immediately before or after the start of the boom. In fact, we find that, on average, denial rates increased, the share of loans with full documentation grew, and the credit quality of borrowers remained constant around early booms. We also find evidence that income in these markets grew faster than the national trend in the years before a local boom. These results suggest that the impetus for the housing booms of the late 1990s were driven more by economic fundamentals, as shown by Ferreira and Gyourko (2011).

In contrast, in markets with late house price booms (after 2000), we find evidence that the increased use of non-traditional mortgage products preceded the accelerated rise of house prices. In the year before the start of late booms, the share of new purchase mortgages with any alternative financing feature increased 5 percentage points, primarily due to the use of variable rate and interest-only mortgage products. Moreover, in late-booming markets, we find important changes to credit supply that occur before the boom begins. For example, we find that mortgage denial rates steadily fell in preceding years. We also see an abrupt shift away from mortgages financed by the Federal Housing Administration (FHA) towards subprime loans in the year immediately before the start of the boom. Strikingly, we find no concurrent shift in "hard information" measures such as borrower FICO scores or LTV ratios that would indicate lower loan quality. These results expand upon earlier patterns documented by Rajan et al. (2015) that lenders altered their loan supply along dimensions that would be less frequently and consistently reported to investors. Overall, these findings support the view that financial innovation in the 2000s contributed to rising house prices by reducing payment constraints.

A key question regarding the county-level patterns we document is: what mechanism drove the expansion of alternative mortgage products in late-booming markets? We first develop a model of the mortgage market that highlights how the relative timing of initial increases in house prices and non-traditional mortgages provides insight into this question. Then, following the methodology laid out in Mian and Suf (2018), we show that the rapid expansion of the private label securities market in mid-2003, pursuant to a sharp increase in Treasury rates, led to an immediate increase in the use of non-traditional mortgage products before a subsequent rise in house price appreciation. The expansion of non-traditional products was especially dramatic in those counties where the securities market was active prior to 2003. In these markets, securitization 
infrastructure was already in place and there were few frictions to rapid expansion of mortgage originations. This pattern suggests that an important mechanism during this period was an exogenous shock to lenders' cost of capital that drove them toward the secondary market, where non-traditional products flourished.

Our results integrate a number of strands of literature focused on the degree to which the housing boom reflected price increases due to changing economic fundamentals versus speculation (Himmelberg et al. 2005; Ferreira and Gyourko 2011; Davidoff 2013). Such research points to the role of investors (Haughwout et al. 2011; Chinco and Mayer 2016), subprime borrowing (Demyanyk and Van Hemert 2011), and nontraditional mortgage products (Amromin et al.|2018; Barlevy and Fisher|2011; Piskorski and Tchistyi 2011; Keys et al.2013). These explanations remain controversial, in part because of the challenge of capturing how expectations of future house price increases affect borrowers' and lenders' mortgage origination choices. We find evidence that financial innovation through an increased use of non-traditional mortgage products was untethered to improvements in local fundamentals in later and more severely booming markets.

Our results also support the centrality of a credit supply expansion in driving the housing boom. For example, Favilukis et al. (2013) find that the primary driver of house price growth was changes in credit supply over the 2000s, while Justiniano et al. (2015) argue that the key stylized facts of the housing boom are best explained by the relaxation of lending constraints. In contrast, Glaeser et al. (2013) argue that the easy credit of the 2000s, through both interest rates and lending standards, cannot account for the substantial price increases. In our study, the timing of alternative financing trend breaks and credit supply changes we document aligns with the findings of Mian and Sufi (2018) and Justiniano et al. (2017), who both identify mid-2003 as a pivotal moment when credit supply strongly deviated from previous trends.

In the next section, we describe our data. Section 3 presents a stylized theoretical model to highlight the ways in which house prices and non-traditional mortgage products interact. Section 4 describes our breakpoint methodology and its application to house prices. Section 5 provides the results of our study for all counties and early- and late-booming counties analyzed separately. Section 6 concludes.

\section{Data and Measurement}

The unique dataset we construct has three key features that make it well-suited to study the relationship between rising house prices and non-traditional mortgage products. First, we are able to observe the house price dynamics of a large number of local housing markets. Importantly, our repeat-sales house price indices 
are based on the sales backed by a large range of loan types rather than just conforming loans. These indices should capture the house price movements of properties financed with non-traditional mortgage products, which is likely to reduce measurement error. Second, we take advantage of administrative loanlevel data that are comprehensive in their geographic and loan characteristic coverage. These data allow us to measure with great precision the prevalence of non-traditional mortgage products for a large number of local markets. To our knowledge we are the first to construct such measures. Third, using multiple years of administrative loan-level data allows us to take measurements at a monthly frequency, which makes it possible to pinpoint sharp changes in our variables and to follow the order in which they occur. In summary, our dataset provides more granularity across three dimensions — the geographic level (county), time period (month), and mortgage-level detail — than any previous study along these lines to the best of our knowledge.

For additional context, although these non-traditional mortgage products were invented earlier, our dataset period from 1993 - 2010 is well suited to studying their relationship to house prices. Their use before that period was limited to certain areas (e.g. California) or individuals (e.g. high credit quality entrepreneurs) who had specific needs for flexibility (Green and Wachter 2005). In the late 1990s, their use began to broaden, as they became more attractive to lenders for several reasons. For one, advances in technology, including automated underwriting and better credit monitoring, made lenders more confident in their ability to assess the risk of such products (Gates et al.2002). In addition, in a healthy economy with rising house prices, lenders may have been more willing to make contracts with incomplete information (Bolton and Faure-Grimaud 2010; Tirole 2009; Piskorski and Tchistyi 2011).

We now discuss each data source in more detail. The county-level house price indices were obtained from CoreLogic (CL). These indices are, for our purposes, preferable to other indices, such as those produced by the Federal Housing Finance Agency (which only include properties backed by conforming loans), or those produced by Case-Shiller (which are limited to a smaller set of markets). At the time of our analysis, CL produced 1,163 county-level house price indices for single-family detached properties using their repeat sales methodology. CL indices have the advantage of going back for many more years than other indices, such as Zillow (though there is considerable overlap between the two sources in recent years). The CL indices start in 1973 for some counties, but we limit our analysis to 1993, when many indices begin, and later. No indices are produced for counties that experience fewer than five sales in a least one month over their collection period. The sample counties cover over 80 percent of the US population. The remaining 20 percent consists of rural counties that experienced very little of the housing boom. 
Our mortgage financing characteristics are from CoreLogic, the Home Mortgage Disclosure Act (HMDA) data, and McDash Analytics, LLC, a wholly owned subsidiary of Lender Processing Services, Inc. (McDash LPS). CL and McDash LPS provide loan-level records for first-lien non-agency (subprime and alt-A) mortgages and agency (mostly prime) mortgages, respectively, for the 1993-2012 period. Both CL and McDash LPS collect these records from a group of mortgage servicers. Their combined coverage of the mortgage market in the early 1990s is less than ideal, 20-40 percent, but grows with the addition of more servicers over time. The data after 2004 covers over 80 percent of the first-lien market. While the representativeness of our data in earlier years and compositional shifts over time are a concern, this data remains the best, if not only, source for detailed information on loan characteristics. Additionally, for the purposes of our analysis, it is unlikely that changes in coverage are correlated with the timing of county-level structural breaks in house prices or our other market variables. The sample is limited to purchase loans since we are interested in the actions of borrowers entering the market, rather than current owners who refinance or extract equity from their homes.

From the CL and McDash LPS data sources, we separately calculate the share of loans with a variable rate, extended term, interest only, or negative amortization feature, as well as two summary measures of the use of non-traditional mortgage products in each county and month 4 The first is the percent of mortgages with any alternative financing feature. The second is the percent of mortgages with a "payment gap," defined as a monthly payment that amortizes the mortgage at a rate less than the payment on a counterfactual 30-year fixed-rate mortgage at prevailing rates. The counterfactual rate is obtained by matching each borrower by FICO score bin (20 points) and LTV ratio bin (10 percentage points) to the prevailing interest rate obtained by borrowers using a 30 -year fixed rate mortgage in the same month 5

For each county and month, we also use this source to calculate the share of loans originated through the FHA, the share with full documentation, as well as average FICO scores at origination and first-lien loan-tovalue ratios. It should be noted that loans insured by the FHA are typically 30 -year fixed-rate mortgages that require a minimum 3.5 percent downpayment. Given the low required downpayment, a borrower choosing a subprime loan over an FHA mortgage would be more likely to experience a reduction in monthly payments or be able to buy a more expensive house using an alternative financing feature, rather than relaxing a

\footnotetext{
${ }^{4}$ For the time series of the prevalence of each non-traditional mortgage feature, see Figure A.1

${ }^{5}$ Less sophisticated approaches to constructing a counterfactual, such as assigning all borrowers in a given month the prevailing Freddie Mac Primary Mortgage Market Survey (PMMS) interest rate on a 30-year fixed rate mortgage, yield qualitatively similar results.
} 
downpayment constraint ${ }^{6}$

We obtain additional mortgage characteristics from HMDA for the same period (1993-2010). Passed by Congress in 1975, HMDA requires every lender satisfying any of a broad list of criteria to report every loan and a set of its characteristics to a central repository $]^{7}$ Because of this requirement, coverage for this dataset is broad. Again, we limit our analysis sample to purchase loans. From this source, we obtain information related to credit supply that are not available in the CL and McDash LPS data. The measures we calculate from HMDA for each county and month include the share of loan applications denied, percent subprime, second lien share of originations, percent owner-occupied, and average debt-to-income ratio ${ }^{8}$

Summary statistics for our data across the full sample are given in Table 1. House price appreciation in our sample counties over our sample period was quite high, on average 8.5 percentage points, with an almost equally high standard deviation. For our summary measures, the percent of mortgages with at least one alternative financing feature and the percent with a payment gap averaged 19.4 percent and 18.2 percent, respectively, but again with very high standard deviations.9 Thus, during an extended period of rising prices, non-traditional mortgages were quite prevalent.

\section{Theoretical Framework}

In this section, we develop a stylized model of a local mortgage market to show how non-traditional mortgages can be both a cause and consequence of house price booms and motivate our empirical investigation. The central insight from the model is that borrowers and lenders use non-traditional mortgage products to (1) maintain affordability of houses in a market with rising house prices and to (2) speculate on those future increases. Furthermore, a fall in the cost of capital that lenders use to supply loans can fuel the speculative use of non-traditional mortgages. The model here borrows heavily from the designs of Barlevy and Fisher (2011) and Relihan (2017) and the insights from other work on the interaction of non-traditional mortgage

\footnotetext{
${ }^{6}$ In addition, FHA loans cannot be larger than a proportion of the conforming loan limit, whereas subprime loans do not face such a cap. See Immergluck (2011) for more on the drivers of the decline in FHA share during the housing boom.

${ }^{7}$ The most important criteria include having assets above a low threshold and operating a branch within an MSA. For a full discussion of reporting requirements see http://www.ffiec.gov/hmda/pdf/2013guide.pdf .

${ }^{8}$ Subprime loans are identified by matching HMDA agency and lender codes with the subprime lender list created by HUD. According to Mayer and Pence (2009), this method should adequately capture the size of the subprime market. HMDA itself includes an indicator for "high-cost" loans in the later years of data, but this measure may not capture whether the loan is actually subprime (given the lack of data on creditworthiness). Additional county characteristics are obtained from the Census and the Bureau of Labor Statistics (BLS). These data sources provide information on household income and county unemployment rates. Since household income is only collected annually, we linearly interpolate monthly values between years.

${ }^{9}$ The small discrepancy between these two measures can be explained by some 15 -year loans with alternative features, which sometimes pay more on a monthly basis than a 30-year fixed rate mortgage.
} 
use and house prices (Campbell and Cocco 2003; ; Piskorski and Tchistyi 2010, 2011; Kung 2015; Guren et al. 2018). However, in contrast to this previous work, we allow for a menu of mortgage types to be an endogenous outcome of the model, rather than presupposing a set of available mortgage contract types or focusing on one optimal mortgage design.

\subsection{Setting}

There are three key elements to our model. First, consumers have different wages so that they differ in their ability to pay for housing services. Consumers with high wages will not pay more than the marginal utility from housing, while lower wage consumers cannot pay more than their wage in any period. Second, there is one lender available, and consumers must use a mortgage to purchase a house. Thus, the lender offers a menu of mortgage types to consumers, with fixed and varying payments matched to consumers' wage profiles, to perfectly price discriminate and fully extract consumers' surplus from owning a house 10

Third, uncertainty about the path of future house prices is common to both consumers and the lender. In the model, this uncertainty generates the speculative use of non-traditional mortgage products. In particular, if the future expected house price is high relative to the house price today, the lender may increase expected profit by shifting the supply of loans toward future consumers. If they do so, the current equilibrium house price and loan size rise, increasing current consumers' leverage relative to wages and/or use of back-loaded mortgages. Without this uncertainty, there would be no speculative use of non-traditional mortgages; Instead, only changes in lenders' cost of capital would alter the product mix.

More formally, in period $t=1$ there is a unit mass of consumers, denoted as generation $g=1$. With some probability $q<1$ another generation of consumers of size $n$ will arrive in the second period. Denote them as generation $g=2$. Once arrived, consumers live an infinite number of periods. Each consumer $i$ in generation $g$ in period $t$ is identical except for her initial wage, $w_{i t}^{g}$, which is independently and identically distributed from some space $W^{g}$. In subsequent periods, each consumer receives an independent shock to their wage such that $w_{i t+1}^{g}=w_{i t}^{g}+\epsilon_{i}^{g}$, where $\epsilon_{i t}^{g}$ is randomly drawn from distribution $E^{g}$. This information is common to all consumers and the lender.

The consumer's problem is to maximize her total lifetime utility, which depends on her consumption

\footnotetext{
${ }^{10}$ At the other extreme, with perfect competition all mortgages would be lent at cost. Therefore, to generate a menu of mortgage contracts with fixed and varying payments, it would be necessary instead to have some other variation such as in risk premiums or credit market frictions.
} 
of housing services through homeownership and consumption of all other goods ${ }^{11}$ The marginal utility of consuming all other goods in a period is normalized to 1 . The relative size of consumers' marginal utility from housing will be crucial in determining the equilibrium house price and mortgage contracts; only consumers who can access housing services for no more than their marginal utility will have demand for a house. Suppressing the generation index, each consumer's problem is:

$$
\max _{\left\{c_{i t}\right\},\left\{M_{i t}\right\}} \sum_{t=1}^{\infty} \beta^{t}\left(c_{i t}+\bar{\mu} M_{i t}\right)
$$

such that

$$
c_{i t} \geq 0, M_{i t} \epsilon\{0,1\} \forall t
$$

and

$$
c_{i t}+p_{i t}\left(L_{i t}\right) M_{i t} \leq w_{i t}+h_{t} M_{i t-1} \forall t
$$

where $\beta$ is the discount rate (identical for all consumers), $c_{i t}$ is consumption of all other goods excluding housing, $M_{i t}$ indicates an outstanding mortgage, $p_{i t}\left(L_{i t}\right)$ is the consumer's mortgage payment for a loan of size $L_{i t}$, and $h_{t}$ is the house price. Per period marginal housing utility is $\mu\left(\beta^{-1}-1\right)$, such that the utility from owning a house in perpetuity is $\bar{\mu}$. Consumers can only purchase a house in the first period of their

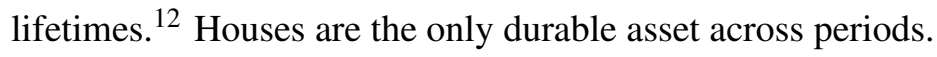

We also assume that there is only one lender and that a mortgage is required to purchase a house. The lender's problem is to choose the consumers in each generation it should offer loans to and the payments on each respective mortgage that maximize its total expected profit:

$$
\max _{\left\{p_{i t}\left(L_{i t}\right)\right\}} \sum_{i} \sum_{t} E\left[\pi\left(M_{i t}\right)\right]
$$

such that

$$
\sum_{i} \sum_{t} E\left[\pi\left(M_{i t}\right)\right] \geq 0
$$

where $E\left[\pi\left(M_{i t}\right)\right]$ is the expected profit from a mortgage made to person $i$ at time $t$. If a consumer defaults

\footnotetext{
${ }^{11}$ For simplicity, we do not discount the future profit for the lender. This does not have any meaningful impact on the model's conclusions.

${ }^{12}$ Without this assumption, a first generation consumer's purchase decision in period 1 is a function of the purchase decisions of other first generation consumers in period 1. Therefore, this assumption makes the model solution more tractable.
} 
on a loan in period $u>t$, the lender takes immediate possession of the house and can resell it to another consumer in period $u$. The lender has recourse to the period $u$ wages of a borrower in default. Therefore:

$$
E\left[\pi\left(M_{i t}\right)\right]= \begin{cases}\sum_{t} E\left[p_{i t}\left(L_{i t}\right)\right]-r & \text { if default not expected } \\ \sum_{t}^{u} E\left[p_{i t}\left(L_{i t}\right)\right]+E\left[h_{u} *\right]+E\left[w_{i u}\right]-r & \text { if default expected }\end{cases}
$$

where $r$ is the fixed cost of making a loan ${ }^{13}$ If two customers are equally profitable, the lender will randomly break ties in allocating loans.

We make several additional assumptions to focus on the space of interesting outcomes. First, we assume that there is a fixed supply of houses, $H^{1}<1$, available in the first period so that some consumers in the first generation will not be able to purchase a house. Second, we assume that the house price in a period is the highest price that clears the market for the available houses, as in a sealed bid auction with multiple units and one price. Third, we assume non-negative expected wage growth in each period to focus on the dynamics of house price booms.

\subsection{Outcomes}

The optimal choices of the first generation consumers and lender depend on their expectation of future house prices. Therefore, we solve for the first period equilibrium house price and mortgage contracts through backward induction. In period 3 and thereafter, because there are no consumers who can purchase houses, the house price is 0 and there is no mortgage market (the degenerate case) ${ }^{14}$ Moving to period 2, if the second generation does not arrive, then the house price and mortgage markets similarly collapse.

Now, imagine the second generation does arrive. Consumers from the second generation will only want to contract for a mortgage if they get at least as much utility from housing through the mortgage as they would from consuming other goods. In other words, their total mortgage payments cannot exceed their maximum lifetime utility from housing: $\sum_{t} p_{i t} \leq \bar{\mu}$. As the sole supplier of mortgages with perfect information, the lender is able to perfectly price discriminate. It will therefore choose to offer each consumer a mortgage contract with the highest payments possible that still satisfies each consumer's budget constraint.

\footnotetext{
${ }^{13}$ We assume a fixed cost to each loan and that lenders offer the smallest profit maximizing loan.

${ }^{14}$ If consumers in the later periods of life were to trade houses among themselves, the house price would still be the smaller of $\bar{\mu}$ and the willingness to pay of the marginal consumer, but solving the model would be significantly less tractable while not providing any extra insight.
} 
For consumers with expected wages above $\mu\left(\beta^{-1}-1\right)$ for all periods, the most the lender can charge is $\mu\left(\beta^{-1}-1\right)$ each period. Other consumers cannot be charged more than their wage in any period. Therefore, in equilibrium, consumers are offered mortgages with both fixed and variable payments such that:

$$
p_{i t} *= \begin{cases}\mu\left(\beta^{-1}-1\right) & \text { if } w_{i 2} \geq \mu\left(\beta^{-1}-1\right) \forall t \\ \min \left(E\left[w_{i t}\right], \mu\left(\beta^{-1}-1\right)\right) & \text { if } w_{i 2}<\mu\left(\beta^{-1}-1\right)\end{cases}
$$

for $t=2, \ldots, \infty$ for borrowers who receive a mortgage. Note that this means there can be mortgages with both fixed and variable payments in equilibrium, even without expectations of future house price increases ${ }^{15}$

The equilibrium house price in period 2 will be determined by the marginal willingness to pay of consumers for housing services. Their willingness is at most $\bar{\mu}$, their lifetime marginal utility from owning a house. Denote the period in which a consumer's wages are expected to exceed $\mu\left(\beta^{-1}-1\right)$ for the first time as period $s$. If the expected sum of a consumer's lifetime wages are less than $\bar{\mu}$ at time $t$, then she would be willing to pay all of the discounted utility from her wages up until date $s, \sum_{t}^{s} \beta^{t} w_{i t}$, and the discounted utility she would receive from owning a house for her remaining lifetime, $\beta^{s-t} \bar{\mu}$, for a house in period $t$.

Denote $H^{2}$ as the mass of houses available for purchase in the second period through defaults and vacancies 16 Then house prices in the second period are determined by the intersection of the housing supply and willingness to pay curves, as illustrated in Figure A.2. If there are fewer houses than second generation consumers whose willingness to pay is $\bar{\mu}$, then the house price that clears the market is $\bar{\mu}$ and a random subset of those consumers will be allocated the $H^{2}$ houses. However, if there are more houses than consumers with the maximum willingness to pay, then the price falls to the willingness to pay of the $k^{\prime}$ consumer that clears the market. Hence:

$$
h_{2} *= \begin{cases}\bar{\mu} & \text { if } \phi^{2}>H^{2} \\ \sum_{t=2}^{s} \beta^{t} w_{k^{\prime} t}+\beta^{s-2} \bar{\mu} & \text { if } 0<\phi^{2} \leq H^{2}\end{cases}
$$

where the mass of consumers in a generation $g$ with initial wages $w_{i}^{g} \geq \mu\left(\beta^{-1}-1\right)$ is $\phi^{g}$. Given the period 2 house prices, the loan size required by each consumer is $L_{i t}=h_{2} *$.

\footnotetext{
${ }^{15}$ Furthermore, since consumers live for infinite periods these are payments on non-amortizing loans and the lender is equivalent to a landlord.

${ }^{16}$ Note that in order for a first generation consumer to sell a house, it must be that $h_{2} *>\bar{\mu}$. This is impossible, so $H^{2}$ will be composed of houses repossessed by the lender and houses which were not sold in period 1.
} 
We have now solved for the period 2 equilibrium mortgage contracts and house price, depending on whether the second generation arrives. If they do not, with probability $(1-q)$, then the house price will be 0 (because there are no new borrowers). If they do, with probability $q$, the house price will be determined as in equation (8). Therefore, in period 1, the expectations of the consumers and lender for period 2 house prices will be:

$$
E\left[h_{2} *\right]= \begin{cases}\bar{\mu} q & \text { if } \phi^{2}>H^{2} \\ \left(\sum_{t=2}^{s} \beta^{t} w_{i^{*} t}+\beta^{s-2} \bar{\mu}\right) q & \text { if } \phi^{2} \leq H^{2}\end{cases}
$$

Lenders will use this expectation to determine which first generation consumers it should provide mortgages. Consumers, who are restricted from purchasing homes outside the period they arrive, do not use this expectation in their borrowing decision.

We now solve for the lender's optimal allocation of loans to first-generation consumers. In each generation, the most profitable borrowers to the lender are those consumers whose wages are expected to be at least $\mu\left(\beta^{-1}-1\right)$ each period once they arrive. If they receive a mortgage, the payments will be equal to that maximum willingness to pay and borrowers would not be expected to default. In the first period, the lender will always prefer to lend to first generation consumers in this group, since they receive one more payment from them. Following the same logic, the next most profitable borrowers are those first-generation consumers who make less than $\mu\left(\beta^{-1}-1\right)$ in the first period, but are expected to make at least that in period 2 and later. For these first-generation consumers, they pay their wage in the first period and $\mu\left(\beta^{-1}-1\right)$ thereafter. They are also not expected to default.

At this point, if there are enough first generation consumers in these two categories to purchase all of the houses, then the mortgage contracts and house price will again be structured as in equations (7) and (8) with a mix of fixed and variable payment contracts. Furthermore, the period 2 house price and mortgage markets will stagnate, as no first generation consumers will sell their house for less than $\bar{\mu}$ and no second generation consumers will buy one for more than $\bar{\mu}$.

Instead, suppose that there are more houses than first generation consumers with wages in the two categories above. The lender then faces a more complicated decision rule for the allocation of additional mortgages among the remaining first generation consumers, those for whom $E\left[w_{i 2}\right]<\mu\left(\beta^{-1}-1\right)$. Call consumer $i^{*}$ the consumer with the highest wages from the remaining first generation consumers who would not default in expectation on a mortgage with payments matched to her expected wage profile. Call consumer 
$j^{*}$ the first generation consumer with the highest wages such $w_{i 1}+\beta E\left[w_{i 2}\right]<\mu\left(\beta^{-1}-1\right)$. This is the highest wage consumer who would prefer a contract on which they expect to default to no mortgage at all. Finally, call consumer $k^{*}$ the second generation consumer with the highest expected willingness to pay in the second period.

The marginal allocation of credit will depend on the relative profitability of lending among these three consumers. For example, If the lender makes its next mortgage to consumer $i^{*}$, the lender's expected profit from the mortgage is:

$$
w_{i^{*} 1}^{1}+E\left[w_{i^{*} 2}^{1}\right]+\sum_{t=3}^{\infty} \min \left(E\left[w_{i^{*} t}^{1}\right], \mu\left(\beta^{-1}-1\right)\right)-r .
$$

But if the lender instead provides the next mortgage to second generation consumer $k^{*}$, its expected profit is:

$$
\sum_{t=2}^{\infty} \min \left(E\left[w_{k^{*} t}^{2}\right], \mu\left(\beta^{-1}-1\right)\right) q-r q .
$$

To maximize expected profits, the lender should allocate the next mortgage to the more profitable consumer. Thus, when the expected profitability of lending to consumer $k^{*}$ is relatively high, the lender begins to restrict its mortgage supply to first generation consumers in favor of speculating on the arrival of profitable second generation consumers. This will be more likely to occur when second generation consumers' wages, the probability of their arrival, or the size of their generation is high.

However, the lender may not need to forgo any period 1 payment in order to lend to consumer $k^{*}$. The lender could first provide a mortgage to consumer $j^{*}$, who would be expected to default in period 2 . Then the lender can both resell the house and lend to second generation consumer $k^{*}$. Under this scenario, the lender's expected profit from mortgages to both $j^{*}$ and $k^{*}$ is:

$$
w_{j^{*} 1}^{1}+E\left[w_{j^{*} 2}^{1}\right]+E\left[h_{2} *\right]+\sum_{t=2}^{\infty} \min \left(E\left[w_{k^{*} t}^{2}\right], \mu\left(\beta^{-1}-1\right)\right) q-r(1+q) .
$$

Lending to both the low-wage first generation consumer $j^{*}$ and second generation consumer $k^{*}$ rather than the second generation consumer alone will be profit maximizing when $w_{j^{*}}+E\left[w_{j^{*} 2}\right]+E\left[h_{2} *\right]-r>0$, i.e. when the wages of the low-wage consumers who default in expectation are high or house prices are high relative to the cost of mortgage origination.

Thus, in this model the lender trades off providing an additional mortgage to a high-wage first generation 
consumer who is not expected to default against speculating on the arrival of the second generation. The lender does so by reserving the option to lend to the highest-wage second generation consumer, possibly in combination with supplying a mortgage to a low-wage first generation consumer who is expected to default in the second period. Once the next loan per period is allocated, the lender will reconsider equations (10), (11), and (12) with the remaining customers and continue allocating loans until all the houses are accounted for or the lender can no longer make a loan with positive expected profits.

The first period house price will again be determined by the lowest marginal willingness to pay of the first generation consumer who can receive a mortgage, consumer $i^{\prime}$, such that:

$$
h_{1} *=\left\{\begin{array}{ll}
\bar{\mu} & \text { if } \phi^{1}>H^{1} \\
\left(\sum_{t=1}^{s} \beta^{t} w_{i^{\prime} t}+\beta^{s-1} \bar{\mu}\right) & \text { if } \phi^{1} \leq H^{1}
\end{array} .\right.
$$

and the loan size of each consumer is $L_{i 1}=h_{1} *$. Note that consumers who expect to default in period 2 have an unlimited willingness to pay for a house in period 1 . Therefore, period 1 house prices and loan sizes are determined by the willingness to pay of the $i^{\prime}$ borrower who does not expect to default. Furthermore, while borrowers who do not expect to default will receive either fixed or variable payment contracts as in equation (7), borrowers who expect to default will accept any payment schedule such that the first period payment is less than their wage. Given their low wages, this implies a back-loaded mortgage contract relative to the borrowers who do not expect to default for the same loan size.

It is worth emphasizing that in this setting, the lender's shift of credit supply toward second generation consumers affects the leverage of first generation consumers through house prices. Each mortgage the lender denies to a high-wage first generation consumer in favor of speculating on the second generation's arrival changes the $i^{\prime}$ first generation consumer to be a consumer with a higher marginal willingness to pay. Thus this shift puts upward pressure on $h_{1} *$. Higher prices induce greater borrowing, so the loan size of each consumer who receives a mortgage in the first period will also be higher. In this case, consumers with lower wages will experience the largest relative increase in leverage, with especially highly leveraged low-wage consumers if back-loaded mortgages are offered to some consumers who are expected to default. 


\subsection{Discussion}

The model clarifies the simultaneous relationship between the use of non-traditional mortgage products and rising house prices. If economic fundamentals, such as wages or employment growth, are expected to improve in the future and raise future house prices, lenders will shift their supply of mortgages to future consumers and non-traditional mortgage products to current consumers to increase their expected profit. This shift then increases current house prices and consumer leverage relative to wages.

Alternatively, a fall in the cost of lending could also lead to greater use of non-traditional mortgages. A lower cost of lending decreases the payments needed by the lender to ensure non-negative profits in expectation. Therefore the lender is willing to originate more back-loaded mortgages with variable payments to consumers farther down the wage distribution. In other words, the causality between non-traditional mortgage products and rising house prices could run in either direction.

Ideally, an exogenous change in house prices or non-traditional mortgage use would provide the clearest evidence of their causal relationship. We use the rise of the private label securitization market in mid-2003 to study one such discrete supply-side change during an era of broad financial liberalization. More generally, the model suggests that the relative timing of initial increases in house prices and non-traditional mortgage use can provide important insight into their relationship. If house prices rise before an increase in the use of non-traditional mortgages, it is more likely to be driven by improvements in expectations over economic fundamentals. However, if the use of non-traditional mortgages rises first, it is more likely the case to be driven by reduced costs to lenders.

\section{Methodological Framework}

We are primarily concerned with studying changes in local mortgage markets around the start of their house price booms. This empirical exercise, of course, requires a definition of the start of a house price boom. Unfortunately, there is no agreed-upon definition of a boom's start, with the empirical literature taking a variety of methodological approaches to identify booms (Himmelberg et al. 2005; Case and Shiller 2003, Mayer 2011). For example, consider the counties in Figure 3, where there is a clear run-up in house price levels and growth rates. Because the trends are not visually discontinuous, additional structure is necessary to define the start of the housing boom for each county.

Our approach is to identify the start of a county's housing boom by using a breakpoint randomization 
methodology that selects the month in which the 12-month house price appreciation rate first deviates most sharply from prior trends. We interpret this large deviation from trend as indicating that the forces driving local house prices changed in a meaningful way. This follows the approach taken by Hansen (2000) and applied to metropolitan housing markets by Ferreira and Gyourko (2011), Charles et al. (2018), DeFusco et al. (2018).

For each county $c$ and month $m$, we run regressions over all possible breakpoints $\lambda_{c m}^{*}$ of the form:

$$
\delta P_{c m}=\alpha_{c}+\beta_{c} \mathbf{1}\left[\lambda_{c m} \geq \lambda_{c m}^{*}\right]+\epsilon_{c m}
$$

In the sample for each county, we only include the months up to and including the month with the largest 12month increase in house price appreciation. This restriction ensures our methodology chooses a structural break associated with the boom in house prices, rather than a break associated with the later bust. Practically, this methodology usually involves running somewhere between 60 and 150 regressions (one for each month observed for a given county from the beginning of the data to the house price peak) for each of the 1,163 counties with an available house price index from CL. From each regression, we recover the sum of squared errors, $S\left(\lambda_{c m}\right)$ and identify the structural breakpoint in house price growth as:

$$
\lambda_{c m}^{* *}=\operatorname{argmin}\left(S\left(\lambda_{c m}\right)\right)
$$

We exclude any county for which this chosen breakpoint is not significant at the 5 percent level $\left[{ }^{17}\right.$ This leaves us with 984 counties in our main analysis sample.

In addition, we allow for the possibility of multiple breaks in a county. As seen in Figure A.3, house price cycles in some markets are more frequent between 1993 and 2007, and there are multiple local maxima in house price appreciation rates. Knowing the timing of a second structural break may help not only to better characterize the data on house prices but may also provide a useful source of variation for estimating the relationship between non-traditional mortgages and house prices. To locate the second house price break, we apply a similar search strategy as with the first - we restrict the search period to six months after the period of highest appreciation to the subsequent period with the second-highest house price appreciation. As with the first house price break, we only consider second breaks that are significant at the 5 percent level

\footnotetext{
${ }^{17}$ In our robustness analysis, we have made our significance threshold more restrictive and our conclusions are little changed. These results are available upon request.
} 
in our analysis 18

After identifying the start of each county's house price boom, we conduct an event study analysis of changes in mortgage features, economic fundamentals, and credit supply around that month. We estimate regressions of the form:

$$
Y_{c m}=\alpha_{c}+\beta f\left(\lambda_{c m}^{*}\right)+g(m)+\gamma X_{c m}+\epsilon_{c m}
$$

where $Y_{c m}$ is an outcome in county $c$ and month $m, \alpha_{c}$ is a county fixed effect, $g(m)$ is a set of calendar time controls, $X_{c m}$ is a vector of county economic fundamentals (income level and unemployment rate), and $f\left(\lambda_{c m}^{*}\right)$ is a vector of relative-year dummies ${ }^{19}$ We normalize the dummies so that the year prior to the house price break in county $c$ is the omitted category (and the corresponding coefficient set to 0 ).

The inclusion of county fixed effects, local fundamentals, and time trends account for important covariates that could impact both non-traditional mortgage use and house prices. For example, Amromin et al. (2018) argue that borrowers using mortgages with alternative features tend to have higher income and more education. Furthermore, because households geographically segregate along these dimensions that also matter for housing markets, it is important to estimate the relationship between house prices and mortgage features within counties over time. Controlling for calendar time accounts for underlying national trends in mortgage and borrower characteristics so that the estimated relationship between house price breaks and these attributes is independent of their macroeconomic trends. Finally, including local shocks to economic fundamentals, like income and unemployment, accounts for time-varying local conditions. Implicitly, the $\beta$ coefficients tell us, within county and apart from pre-existing national trends and local changes in economic fundamentals, the difference in appreciation, mortgage attributes, or credit supply in the years around the start of the local house price boom.

In addition to this event study analysis around the start of a county's house price boom, we compare the timing of structural breaks in house prices to the timing of structural breaks in each alternative financing feature. That is, rather than searching for house price breaks, as in Equation (14), we search for countyspecific breaks in our alternative financing variables. If the housing boom occurs before a break in the share of mortgages with any alternative financing feature, for example, we would find it more challenging to infer

\footnotetext{
${ }^{18}$ We also explored searching for additional breaks using this sequential methodology, but given that many breaks occur in 2004 or later, we identify no counties with three or more breaks during this time period given our approach, which searches for the first break using the global maximum. An approach which exploited more local maxima could, with additional restrictions, potentially identify more than two breaks.

${ }^{19}$ In specifications where the dependent variable is an economic fundamental, we omit the additional $X_{c m}$ controls.
} 
that shifts in financing caused the housing boom.

Our approach to applying break point techniques differs from other break point studies due to an important data restriction. Other breakpoint studies typically split their sample into two parts: one that they use to estimate the breakpoint, and another to estimate the size of the jump (e.g. Card et al.2011). In doing so, some issues related to specification search bias can be ameliorated (Leamer 1983). We are unable to do this because we take our house price indices as given, rather than calculated directly from microdata. Our analysis applies already-constructed house price indexes from CoreLogic because we would otherwise need either: (1) the exact property address to construct our own repeat-sales index or (2) detailed property attributes (such as square footage, number of bedrooms) to estimate a hedonic index. Because we have neither, we do not have the ability to construct a credible house price series with our loan-level data. To gauge how our conclusions might be affected by this issue, we conduct robustness analysis where we weight our analysis using the t-statistic for $\lambda^{*}$ that is obtained when estimating Equation (16). We also compare the distribution of our house price breaks those found in studies that apply a split sample approach (e.g. Ferreira and Gyourko 2011; DeFusco et al. 2018). These analyses suggest that our conclusions would be little changed if we were to apply a split sample approach, and these results are available upon request.

\section{Results}

\subsection{National Trends}

Figure 1 shows that, for the U.S. as a whole, house price appreciation and the use of non-traditional mortgage products peak at roughly the same time during the housing boom. When we apply our breakpoint methodology to these national trends between 2000 and 2007, we find that the start of the national house price boom occurs in March 2004, when national house price appreciation exceeded 12 percentage points for the first time in decades, and that the structural break in the national share of loans with any alternative financing feature occurs in September 2003, preceding the national boom by six months (results not shown). This national comparison suggests that the use of non-traditional mortgage products may have contributed to the acceleration in house prices.

However, while suggestive, geographic differences indicate that the national trends are not adequately informative of the relationship between non-traditional mortgage products and rising house prices. For example, Figure 4 shows that the share of loans with an alternative financing feature increased much more 
sharply in the "sand" states (Arizona, California, Florida, and Nevada) relative to the rest of the country. This implies that features particular to local mortgage markets may help explain the wider dynamics of the national housing boom.

\subsection{Measurement of local house price booms}

We find substantial heterogeneity in the timing and size of house price booms at the local level, immediately challenging the notion of a single, national house price boom (see, e.g. Ferreira and Gyourko (2011) for similar results). Figure 5 shows histograms of the timing and size of the first and, where they exist, second house price breaks using our breakpoint methodology on the 1,163 counties with a house price index ${ }^{20}$ The majority of the first structural breaks occur between 1998 and 2006, with 1998 being a particularly notable year due to the tech boom in Coastal California and the Northeast. Another surge in local house price breaks occurs in 2004, which aligns with the national trend. Among the 452 counties with a second house price break, their occurrence is clustered quite late over the period we study; 20 percent occur between mid-2004 and mid-2005, when many other counties experience the start of their first house price boom.

Based on applying our event study approach in equation (16), Figures 6 and 7 present the full path of house price appreciation in the years before and after the booms, allowing the paths to differ by whether the counties experienced early (pre-2000) and late (post-2000) booms and whether the boom is the first or the second, respectively. For their first breaks, early-booming markets experience an average increase in appreciation of 5.5 percentage points, relative to 4.0 percent in the year before, and late-booming markets experience an average increase of 8.0 percentage points, relative to 6.1 percent in the year before ${ }^{21}$ In addition, counties with two house price breaks tend to experience breaks of smaller magnitude overall, with the second slightly smaller than the first. Thus, conditions in the 2000s produced substantial housing booms — even in counties with a history of recent housing booms.

In Table 2, we show that the inclusion of controls for national trends and local economic shocks has no meaningful impact on our results, suggesting these are largely unconnected with the size of local booms. In the first column of panel (a), we show the average magnitude of the boom at period $m=1$ across all counties' first breaks, controlling only for county fixed effects for the within-county comparison. Including the remaining controls for our preferred specification in column (2), we account for national macroeconomic

\footnotetext{
${ }^{20}$ As mentioned above, out of our 1,163 local markets, 179 of these markets did not experience a (statistically significant) housing boom during this time period.

${ }^{21}$ See Table A.1 for summary statistics in the year prior to break.
} 
conditions and shocks to local fundamentals. The inclusion of additional controls, including flexible time fixed effects and economic conditions, has only a minor impact on our estimates. Panel (b) of Table 2 shows a similar pattern for second breaks, with the inclusion of controls generally increasing the estimated size of the house price break for second breaks.

\subsection{Alternative mortgage products in early- versus late-booming markets}

Figure 8 contrasts the use of alternative mortgage products between pre-2000 and post-2000 house price breaks. We find that early-booming markets show no notable shift toward the use of non-traditional mortgage products; if anything, their use was relatively infrequent and on the decline before 2000. In contrast, increased use of these products strongly predated rapidly rising house prices in late-booming markets. In late-booming markets, our summary measures - the percent of purchase originations with any alternative financing feature and the percent with a payment gap — show a sizable and quantitatively significant increase in the year preceding late booms and for several years thereafter. This growth is driven by a notable increase in the share of mortgages with variable rates and interest-only features before late booms, while the shares with extended terms or negative amortization appear to increase only after the start of late booms. These results suggest that the most exotic products may be less attractive to borrowers and lenders, perhaps because of their more limited impact on lowering monthly payments. Their increased use after the start of the boom highlights the need to use non-traditional products to maintain affordability in late periods when house price levels were high. Furthermore, these findings show that the patterns we presented for Clark County, Nevada (see Figure 2), were indicative of a wider set of late-booming markets.

Table 3 provides additional support for the view that increased use of non-traditional mortgage products played a contributing role in house price growth in late-booming markets and less so in early-booming markets. Here, we show the results obtained from estimating structural breaks for each of our financing measures. Then we compare the timing of house price breaks with the timing of breaks in alternative financing. In the early-booming markets, we find that the financing structural breaks almost always occur after the house price breaks across a large majority of markets. This result supports, at best, an indirect role for financing in explaining the start of early booms, although it may help to explanation booms' continuation. In contrast, structural breaks in financing in late-booming markets are more likely to occur before house price booms (or at the same time) relative to early-booming areas. These results are consistent with relaxed 
financing constraints playing a contributing role to the start of later booms 22

\subsection{Alternative mortgage products in counties with multiple booms}

Figure 9 shows that among counties that experienced two house price breaks, the pattern continues to hold in which later booms (recall that a majority of the second booms start between mid-2004 and mid-2005) are most strongly preceded by a surge in the use of non-traditional mortgages and a shift from FHA to subprime loans ${ }^{23}$ This pattern lends further evidence that the broader macroeconomic conditions of the early 2000s particularly drove the speculative use of these products during that period. Furthermore, we note that second booms see a more prominent increase in the prevalence of non-traditional mortgages, even without explicitly conditioning on whether the boom is before or after 200024

\subsection{Mechanisms}

\subsubsection{Fundamentals and Credit Supply around House Price Breaks}

As outlined in the model, changes in expectations versus lending costs suggest different mechanisms for shifting the equilibrium mortgage outcomes in local housing markets. Improvements in economic fundamentals can positively impact expectations such that lenders offer more mortgages and more affordable products. A decline in the cost of lending, as is plausible during the financial liberalization after 2000, would decrease the payments necessary for a lender to make positive profits in expectation, leading to an expansion in credit supply. Therefore, we now examine whether shifts in economic fundamentals and credit supply accord with our observation that the increased use of non-traditional mortgage products was more likely to follow early booms and predate late booms.

We find evidence that early-booming markets were more likely propelled by improving economic conditions in the late 1990s rather than speculative use of non-traditional mortgage products. Figure 10 shows that before early booms, counties experienced an upward trend in income, beyond the upward national trend 25 Furthermore, borrowers living in early-booming markets faced rising denial rates and stricter documentation standards in the years around the structural break in house prices (Figure 11). These findings for early mar-

\footnotetext{
${ }^{22}$ Table A.7 shows similar results for first versus second breaks.

${ }^{23}$ See Tables A.5 and A.6 for point estimates concurrent with break points.

${ }^{24}$ Table A.8 shows results for an alternative specification that looks at early and late booms across first and second house price breaks shows that our conclusions hold in the cross-comparison as well.

${ }^{25}$ See Table A.4 for point estimates concurrent with break points.
} 
kets are consistent with those of Ferreira and Gyourko (2011), which suggest that that fundamental factors outside mortgage markets best explain these early booms.

In stark contrast, late-booming markets experience significant shifts in the supply of mortgage credit that predate the start of local house price booms. Most dramatically, in Figure 11, loan originations targeted toward lower credit-quality borrowers shifted from FHA-backed loans to subprime loans. At the same time, denial rates steadily decreased over the pre-period. It is notable that, at the same time, documentation, average borrower FICO scores, LTV ratios, use of second liens, and the share of owner occupiers show very little trend in the pre-period (again controlling for time-invariant county conditions, macroeconomic trends, and local shocks to economic fundamentals). Rather than observing a sharp deterioration in all underwriting standards directly contributing to house price acceleration, our approach allows us to isolate precisely which features were changing prior to the rise in prices ${ }^{26}$

The patterns we observe around the start of late local house price booms are also informative of lenders' strategic decisions when interacting with secondary securitization markets in this period. Consistent with the results of Rajan et al. (2015), despite a shift toward lower quality loans after the start of booms, as measured by percent owner-occupied and percent with full documentation, hard information measures that would be well observed by investors show no signs of deterioration. In particular, there are no trends before or after the start of late local booms in borrowers' FICO scores. In addition, LTV scores show a downward trend, driven by a shift of mortgage debt towards second liens. As junior liens were frequently under-reported to investors, this reflects another margin on which lenders could obscure the risk of a loan Ghent et al. (2018); Griffin and Maturana (2016).

\subsubsection{Examining Alternative Mortgage Products around the 2003 Treasury Rate Increase}

Our result that the increased use of non-traditional mortgage products preceded accelerated house price growth is consistent with the work of others on financial liberalization during the last decade (Levitin and Wachter 2011; Favilukis et al. 2013; Justiniano et al. 2015). For example, Mian and Sufi (2018), building on the work of Justiniano et al. (2017), exploit the dramatic increase in Treasury rates in mid-2003 for plausibly exogenous variation in lenders' financing constraints. Mian and Sufi show that in response to higher Treasury rates and the concurrent collapse of mortgage refinancings, lenders rapidly expanded their use of the private-label securities market to finance new mortgage origination. This led to a sharper increase

\footnotetext{
${ }^{26}$ See Figures A.4 and A.5 for event study results that are not split by early- and late-breaking counties.
} 
in mortgage supply and house prices in zip codes with higher shares of lenders connected to the private secondary market - that is, those lenders that relied more on non-core deposits prior to the increase in Treasury rates (also known as non-core lenders, or NCL).

To further explore the mechanisms underlying our county-level analysis of non-traditional mortgage products, we also leverage the 2003 shock to Treasury rates. In Figure 12, we show that, in addition to higher prices (panel (a)), counties exposed to a higher share of NCL also experienced an immediate increase in the use of non-traditional mortgage products following the 2003 increase (panel (b)) ${ }^{27}$ Notably, while the growth in alternative mortgage products is instantaneous in mid-2003, house prices appreciate most sharply in the top three quartiles of the non-core deposit distribution of counties, but only after 6-12 months. In addition, across each quartile of exposure to non-deposit lenders, growth in alternative mortgage products increased monotonically with the share of NCL.

In Figures 13 and 14 , we decompose changes in the use of alternative mortgage products into changes in separate products and examine concurrent changes in credit supply after the 2003 increase in Treasury rates. Figure 13 shows that variable rate and interest only products experienced the most substantial, immediate differential increases. In counties with the highest NCL exposure, we measure increases of 6.7 and 5.7 percentage points in these two measures, respectively as compared to counties with the lowest exposure one year after the shock. The changes in credit supply are also strikingly similar to the patterns observed across all late-booming markets in our full analysis. In Figure 14, we find that lenders' credit supply shifted strongly away from FHA toward subprime loans, with high NCL exposure counties experiencing a 2 percentage point greater change compared to low NCL counties. Declines in owner-occupancy and full documentation and a rise in second liens are also observed, while FICO scores and LTV ratios again show little movement.

Overall, these results provide new evidence that non-traditional mortgage products were used to rapidly expand the supply of mortgage credit on a national scale through the private label securities market in response to the increase in Treasury rates 28 This shock immediately relaxed the monthly payment constraint, without altering FICO or LTV standards. Combining this point-in-time estimate of the market response to a cost of lending shock with our broader macroeconometric time-series approach, we conclude that credit supply expansions that facilitated the use of non-traditional mortgage products played a central role in late-

\footnotetext{
${ }^{27}$ To construct this measure of exposure, we merge HMDA data with banks' Call Report data from 2002. We thank Neil Bhutta for providing his lender-ID crosswalk across these datasets. For each lender, we calculate the share of liabilities that are non-core deposits, and then scaled to the county level by weighting by each lender's dollar value of mortgage originations in the county in 2002.

${ }^{28}$ For regression results see tables A.9 and A.10
} 
booming markets where incomes were mostly stagnant.

\section{Conclusion}

In this paper, we aim to disentangle the timing of house price growth with the use of non-traditional mortgage products during the housing boom. To do so, we compile a novel dataset on county-level house prices and mortgage contracts, and use transparent methods to identify the timing of the introduction and growth of the use of these non-traditional products. During the housing boom of the 2000s, the growth in the use of non-traditional mortgage products was as spectacular as the rise in house prices. We find that in many local housing markets where the start of the boom occurred after 2000, greater use of non-traditional mortgage products preceded the boom in house prices, providing suggestive evidence that loosening households' financing constraints contributed to rising prices. In contrast, markets where booms started earlier (prior to 2000) show no such relationship.

Our separate analysis of early- versus late-booming counties shows the importance of treating the housing boom as a local, heterogeneous event. Counties with the start of their house price booms before 2000 show few changes in the composition of mortgage activity, but we estimate gains in median income in these markets. This result complements the findings of Ferreira and Gyourko (2011) and supports the view that the initial house price boom of the late 1990s was driven by economic fundamentals. In contrast, the acceleration of house prices, the use of alternative mortgage products, and the expansion of credit are most closely linked in late-booming (post-2000) counties. Furthermore, our evidence suggests that non-traditional mortgage products allowed borrowers to maintain affordability even as they contributed to rising prices.

By using a time-series breakpoint methodology as our primary empirical approach, our work has necessarily focused on the start of local house price booms, rather than their evolution over time. An important and nascent body of research focuses on how a boom changes into a "bubble" in which prices become unmoored from market fundamentals (see, e.g. Mayer 2011). Our approach regarding how high house prices led borrowers to use non-traditional mortgage products to maintain affordability ignores the feedback effects of these products during the bubble period. Whether there were important feedback effects remains a topic for future research. Our research also helps to explain why the use of non-traditional mortgage products first started to increase in late-booming markets through our examination of the mortgage market's 2003 response to rising Treasury rates, consistent with Justiniano et al. (2017) and Mian and Sufi (2018). 
In the wake of the crisis, regulators have placed significant limitations on a number of the alternative mortgage features discussed in this paper by excluding them from the definition of a "Qualified Mortgage" for regulatory purposes. As laid out by the Consumer Financial Protection Bureau (CFPB) in their January 2013 report, lenders will no longer be able to underwrite a qualified mortgage loan based on a "teaser" rate in determining ability to pay ${ }^{29}$ Moreover, mortgages cannot contain interest-only, negative amortization, or extended term features if lenders want to meet the legal presumption of complying with the qualified mortgage regulation. As we have shown, whether restricting these contract features will affect the formation and magnitude of housing price cycles in the future depends crucially on the context of the use of these features. Although these rules have only recently come into effect, the consequences of limiting these products is also likely to reduce credit access for some households, while guiding others into more standard contracts. These rules may complement other efforts to encourage mandatory mortgage counseling (Agarwal et al. 2014b). Even with these shifts in the composition of borrowers and their contracts, our results show that banning these products is unlikely to eliminate housing booms altogether. Going forward, especially as interest rates rise, the consequences of these regulatory changes for the interaction between non-traditional mortgage products and house prices is a promising area of future research.

\footnotetext{
${ }^{29}$ See the CFPB report on ability to repay rules and qualified mortgages: http://files. consumerfinance.gov/f/201301_ cfpb_ability-to-repay-rule_what-it-means-for-consumers.pdf
} 


\section{References}

Agarwal, Sumit, Gene Amromin, Itzhak Ben-David, and Douglas D Evanoff, "Loan Product Steering in Mortgage Markets," Technical Report, National Bureau of Economic Research 2016.

_, _, _, Souphala Chomsisengphet, and Douglas D Evanoff, "Predatory Lending and the Subprime Crisis," Journal of Financial Economics, 2014, 113 (1), 29-52.

${ }_{-}, \ldots, \ldots, \ldots$, and Douglas Evanoff, “The Effectiveness of Mandatory Mortgage Counseling: Can One Dissuade Borrowers from Choosing Risky Mortgages?," Working Paper No. 19920, National Bureau of Economic Research 2014.

Amromin, Gene, Jennifer Huang, Clemens Sialm, and Edward Zhong, "Complex Mortgages," Review of Finance, 2018.

Barlevy, Gadi and Jonas D. M. Fisher, "Mortgage Choices and Housing Speculation," Working Paper 2010-12, Federal Reserve Bank of Chicago June 2011.

Bolton, Patrick and Antoine Faure-Grimaud, "Satisficing Contracts," The Review of Economic Studies, 2010, 77 (3), 937-971.

Campbell, John Y. and João F. Cocco, "Household Risk Management and Optimal Mortgage Choice," The Quarterly Journal of Economics, 2003, 118 (4), 1449-1494.

Card, David, Alexandre Mas, and Jesse Rothstein, "Are Mixed Neighborhoods Always Unstable? TwoSided and One-Sided Tipping," in Harriet B. Newburger, Eugenie Birch, and Susan Wachter, eds., Neighborhood and Life Chances: How Place Matters in Modern America, University of Pennsylvania Press, 2011, chapter 14.

Case, Karl E. and Robert J. Shiller, "Is There a Bubble in the Housing Market?," Brookings Papers on Economic Activity, 2003, 2003 (2), 299-342.

Charles, Kerwin Kofi, Erik Hurst, and Matthew J. Notowidigdo, "Housing Booms and Busts, Labor Market Opportunities, and College Attendance," American Economic Review, 2018.

Chinco, Alex and Christopher Mayer, "Misinformed Speculators and Mispricing in the Housing Market," The Review of Financial Studies, 2016, 29 (2), 486-522.

Davidoff, Thomas, "Supply Elasticity and the Housing Cycle of the 2000s," Real Estate Economics, 2013, 41 (4), 793-813.

DeFusco, Anthony, Wenjie Ding, Ferreira Ferreira, and Joseph Gyourko, "The Role of Contagion in the Last American Housing Cycle," Working Paper, The Wharton School University of Pennsylvania 2018.

Demyanyk, Yuliya and Otto Van Hemert, "Understanding the Subprime Mortgage Crisis," The Review of Financial Studies, 2011, 24 (6), 1848-1880. 
Favilukis, Jack, David Kohn, Sydney C. Ludvigson, and Stijn Van Nieuwerburgh, "International Capital Flows and House Prices: Theory and Evidence," in Edward L. Glaeser and Todd Sinai, eds., Housing and the Financial Crisis, University of Chicago Press, 2013, pp. 301-360.

Ferreira, Fernando and Joseph Gyourko, "Anatomy of the Beginning of the Housing Boom: U.S. Neighborhoods and Metropolitan Areas, 1993-2009," Working Paper 17374, National Bureau of Economic Research August 2011.

Gates, Susan Wharton, Vanessa Gail Perry, and Peter M Zorn, "Automated Underwriting in Mortgage Lending: Good News for the Underserved?," Housing Policy Debate, 2002, 13 (2), 369-391.

Ghent, Andra C., Kristian R. Miltersen, and Walter N. Torous, "Second Mortgage: Valuation and Implications for the Performance of Structured Financial Products,” Working Paper April 2018.

Glaeser, Edward L, Joshua D Gottlieb, and Joseph Gyourko, "Can Cheap Credit Explain the Housing Boom?," in Edward L. Glaeser and Todd Sinai, eds., Housing and the Financial Crisis, University of Chicago Press, 2013, pp. 301-360.

Green, Richard K and Susan M Wachter, "The American Mortgage in Historical and International Context," Journal of Economic Perspectives, 2005, 19 (4), 93-114.

Griffin, John M and Gonzalo Maturana, "Who Facilitated Misreporting in Securitized Loans?," The Review of Financial Studies, 2016, 29 (2), 384-419.

Guren, Adam M., Arvind Krishnamurthy, and Timothy J. McQuade, "Mortgage Design in an Equilibrium Model of the Housing Market," Working Paper 24446, National Bureau of Economic Research March 2018.

Hansen, Bruce E., “Sample Splitting and Threshold Estimation,” Econometrica, 2000, 68 (3), 575-603.

Haughwout, Andrew, Donghoon Lee, Josephy Tracy, and Wilbert van der. Klaauw, "Real Estate Investors, the Leverage Cycle, and the Housing Market Crisis," Staff Reports 514, Federal Reserve Bank of New York September 2011.

Himmelberg, Charles, Christopher Mayer, and Todd Sinai, "Assessing High House Prices: Bubbles, Fundamentals and Misperceptions," Journal of Economic Perspectives, December 2005, 19 (4), 67-92.

Immergluck, Dan, "From Minor to Major Player: the Geography of FHA Lending During the US Mortgage Crisis," Journal of Urban Affairs, 2011, 33 (1), 1-20.

Justiniano, Alejandro, Giorgio E. Primiceri, and Andrea Tambalotti, "Credit supply and the Housing Boom,” Working Paper 20874, National Bureau of Economic Research 2015.

_, _, and _ , "The Mortgage Rate Conundrum," Working Paper 23784, National Bureau of Economic Research 2017. 
Keys, Benjamin J., Tanmoy Mukherjee, Amit Seru, and Vikrant Vig, "Did Securitization Lead to Lax Screening? Evidence from Subprime Loans," The Quarterly Journal of Economics, 2010, 125 (1), 307362.

_ , Tomasz Piskorski, Amit Seru, and Vikrant Vig, "Mortgage Financing in the Housing Boom and Bust," in Edward L. Glaeser and Todd Sinai, eds., Housing and the Financial Crisis, University of Chicago Press, 2013, pp. 143-204.

Kung, Edward, “Mortgage Market Institutions and Housing Market Outcomes,” Working Paper, University of California-Los Angeles March 2015.

Leamer, Edward E., "Let's Take the Con Out of Econometrics," The American Economic Review, 1983, $73(1), 31-43$.

Levitin, Adam J. and Susan M. Wachter, "Explaining the Housing Bubble," Georgetown Law Journal, 2011, 100, 1177.

Mayer, Christopher, “Housing Bubbles: A Survey,” Annual Review of Economics, 2011, 3 (1), 559-577.

- and Karen Pence, "Subprime Mortgages: What, Where, and to Whom?," in Edward L. Glaeser and John M. Quigley, eds., Housing Markets and the Economy: Risk, Regulation, and Policy: Essays in Honor of Karl E. Case, Cambridge, MA: Lincoln Institute of Land Policy, 2009.

Mian, Atif and Amir Sufi, "The Consequences of Mortgage Credit Expansion: Evidence from the U.S. Mortgage Default Crisis," The Quarterly Journal of Economics, 2009, 124 (4), 1449-1496.

_ and _ , "Fueling a Frenzy: Private Label Securitization and the Housing Cycle of 2000 to 2010," Working Paper, University of Chicago March 2018.

Piskorski, Tomasz and Alexei Tchistyi, "Optimal Mortgage Design," The Review of Financial Studies, 2010, 23 (8), 3098-3140.

_ and _ , "Stochastic House Appreciation and Optimal Mortgage Lending," The Review of Financial Studies, 2011, 24 (5), 1407-1446.

Rajan, Uday, Amit Seru, and Vikrant Vig, "The Failure of Models That Predict Failure: Distance, Incentives, and Defaults," Journal of Financial Economics, 2015, 115 (2), 237-260.

Relihan, Lindsay, “Branches in Local Mortgage Markets,” Working Paper, The Wharton School, University of Pennsylvania March 2017.

Sinai, Todd M., "House Price Moments in Boom-Bust Cycles," in Edward L. Glaeser and Todd Sinai, eds., Housing and the Financial Crisis, University of Chicago Press, 2013, pp. 301-360.

Tirole, Jean, "Cognition and Incomplete Contracts," American Economic Review, March 2009, 99 (1), 265-94. 
Figure 1: Alternative Financing Features and National House Prices

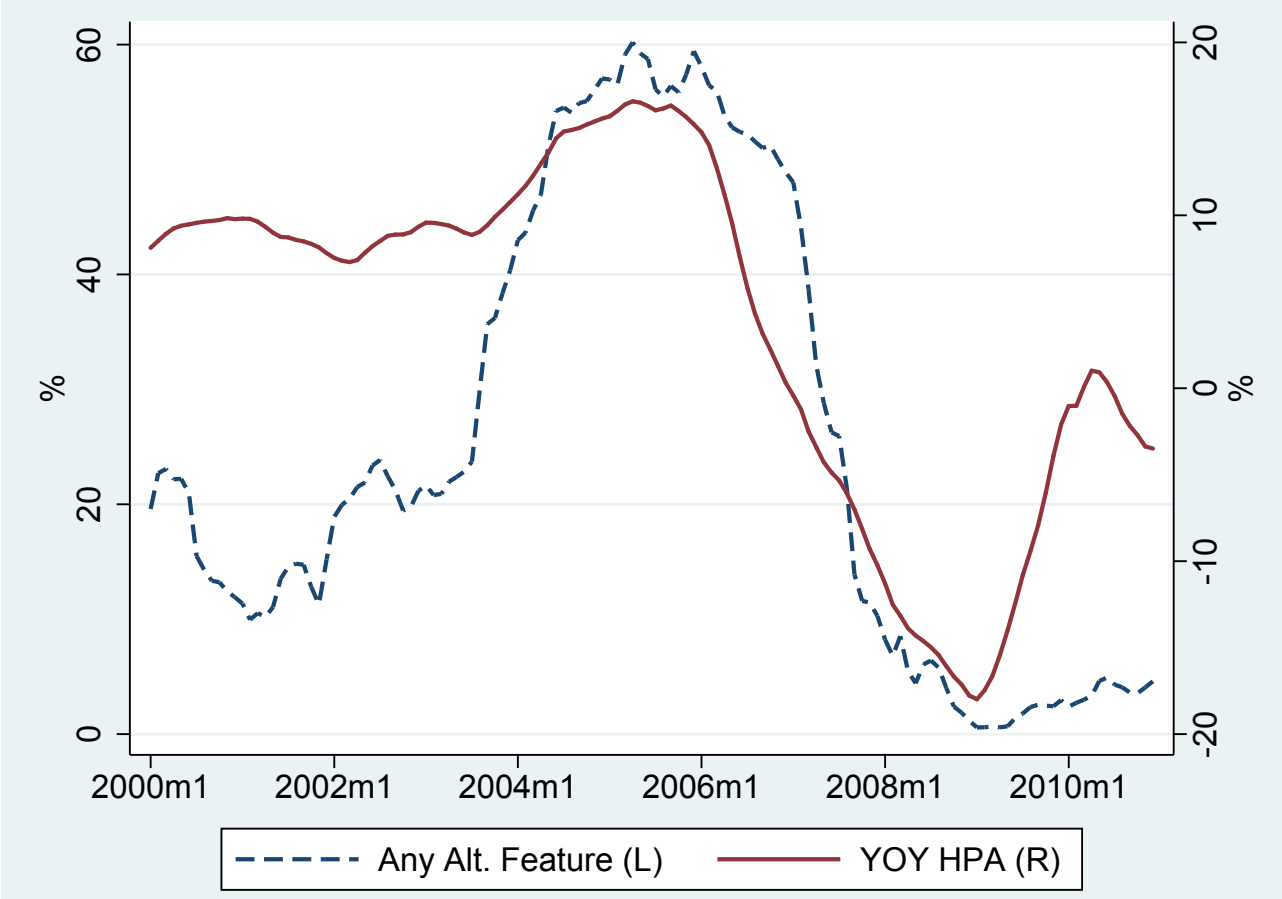

Note: The figure shows the fraction of purchase loans originated in a given month with any alternative financing feature (blue line, left y-axis), as well as 12-month house price appreciation at the national level (red line, right y-axis). The alternative financing features are those that reduce the monthly payment relative to a fully amortizing 30-year fixed rate mortgage payment: teaser variable rate, extended term, interest-only, or negative amortization. See text for details. 


\section{Figure 2: Clark County Estimated House Price Break and Non-traditional Mortgages}

(a) Estimated House Price Break

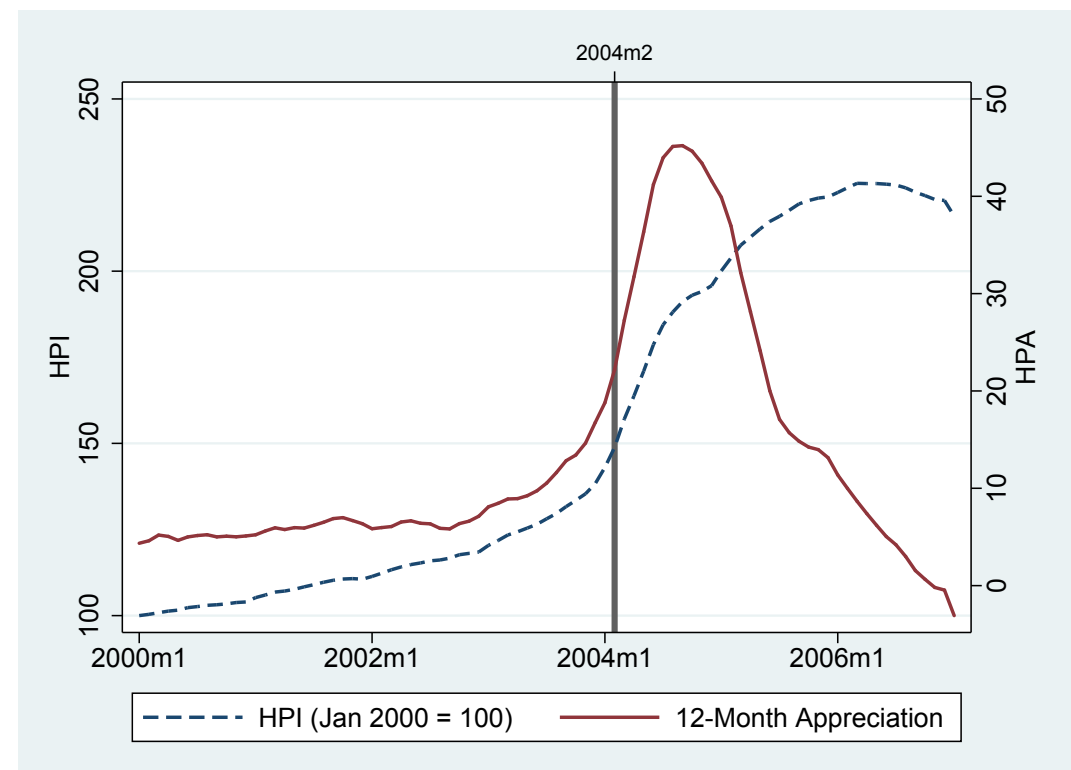

(b) Use of Alternative Mortgage Products

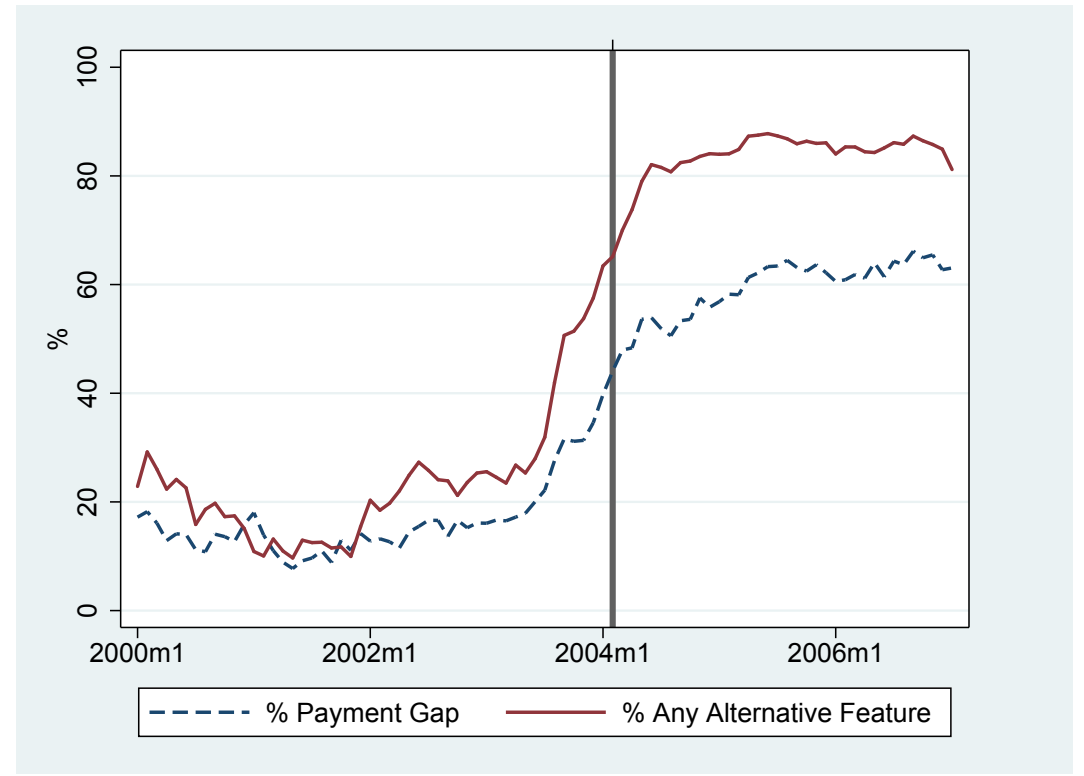

Note: The figure shows the timing of the estimated house price break in Clark County, NV, which is where Las Vegas is located. House price break is estimated using a break-point methodology described in the text. The upper figure shows both the level of house prices (the blue dashed line, and the left y-axis) and the 12-month house price appreciation rate (the red line and corresponding right $y$-axis). The lower figure shows the fraction of purchase loans with a "payment gap," or any deviation from the fully amortizing 30-year fixed-rate mortgage payment (blue dashed line), and the share with any alternative financing feature (solid red line) in Clark County, NV. The vertical line represents the month in which the house price break occurred. 
Figure 3: Sample Counties with Only One House Price Break
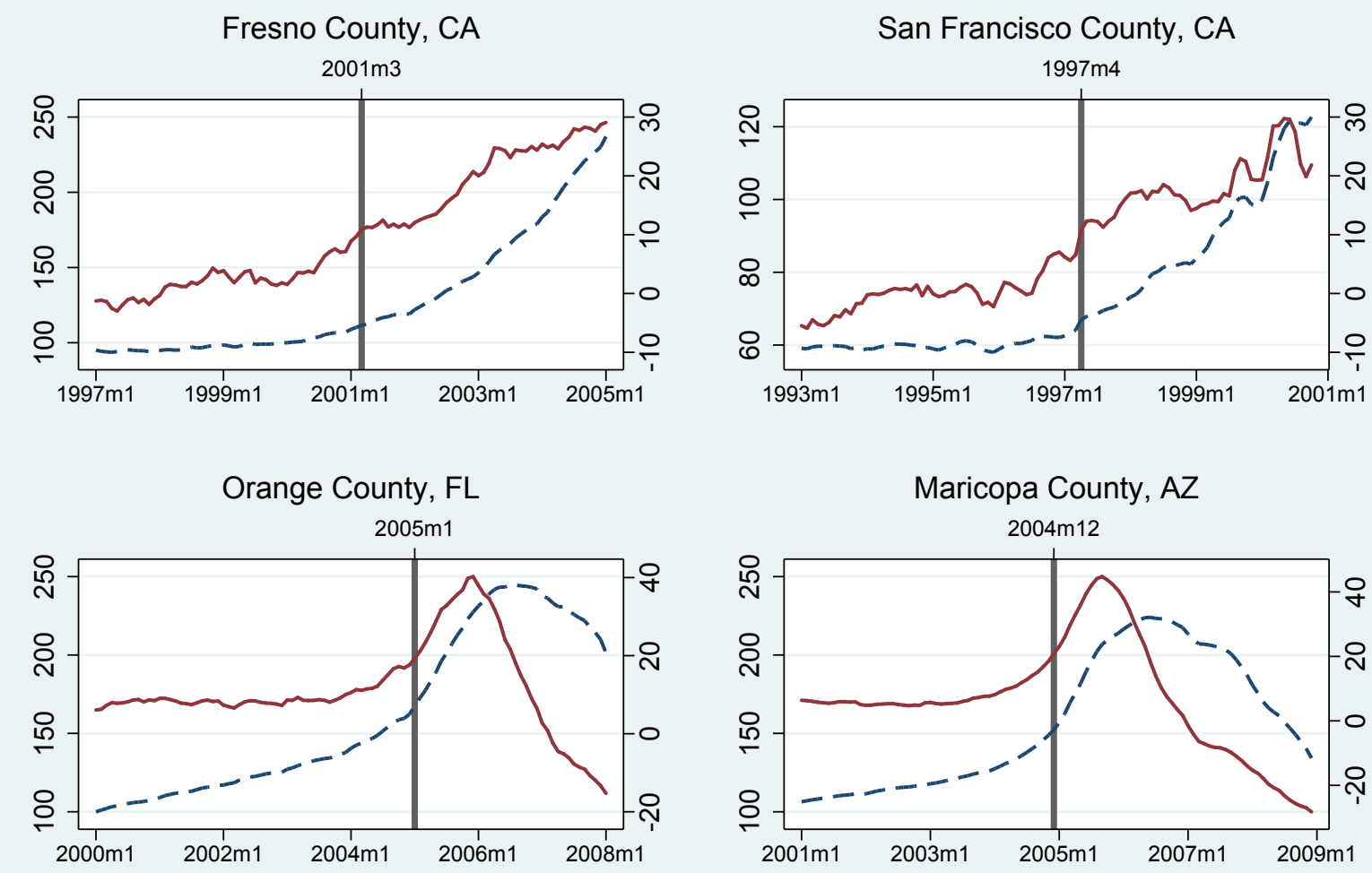

House Price Index $(\operatorname{Jan} 2000=100)$

12-Month Appreciation

Note: The figure shows the timing of structural house price breaks in four counties with only one break: Fresno County, CA (top left), San Francisco County, CA (top right), Orange County, FL (bottom left), and Maricopa County, AZ (bottom right). Structural breaks estimated using break-point methodology described in the text. Each panel shows both the house price index (blue dashed line) and 12-month appreciation rate (red line). 
Figure 4: Alternative Financing by Sand and Non-sand States

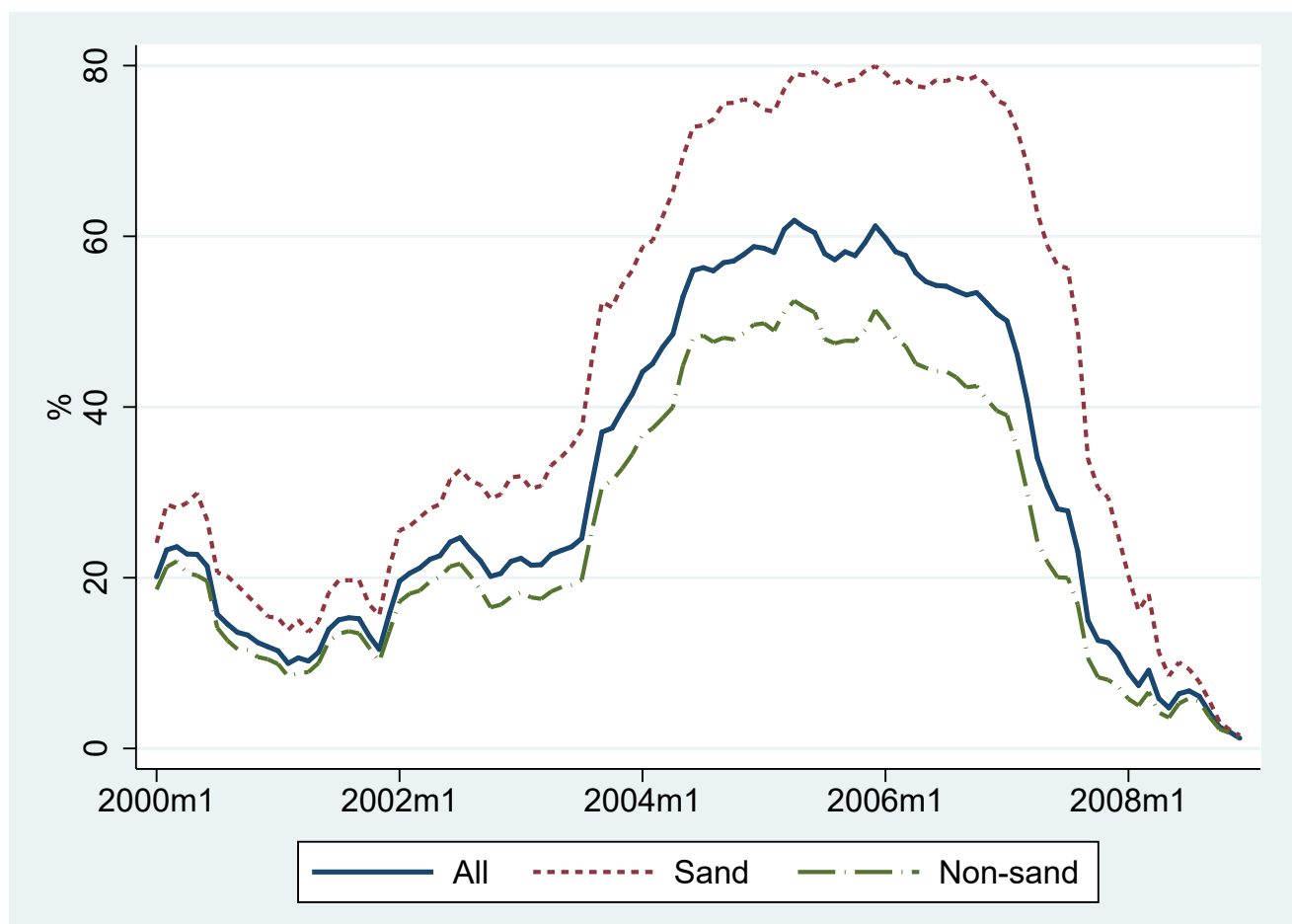

Note: The figure shows the share of loans with any alternative financing feature by "sand" states (Arizona, California, Nevada, and Florida) versus "non-sand" states. The figure shows an increase in the share beginning in mid-2003, particularly in sand states. 
Figure 5: Distribution of House Price Breaks with Average Magnitude

(a) First House Price Break

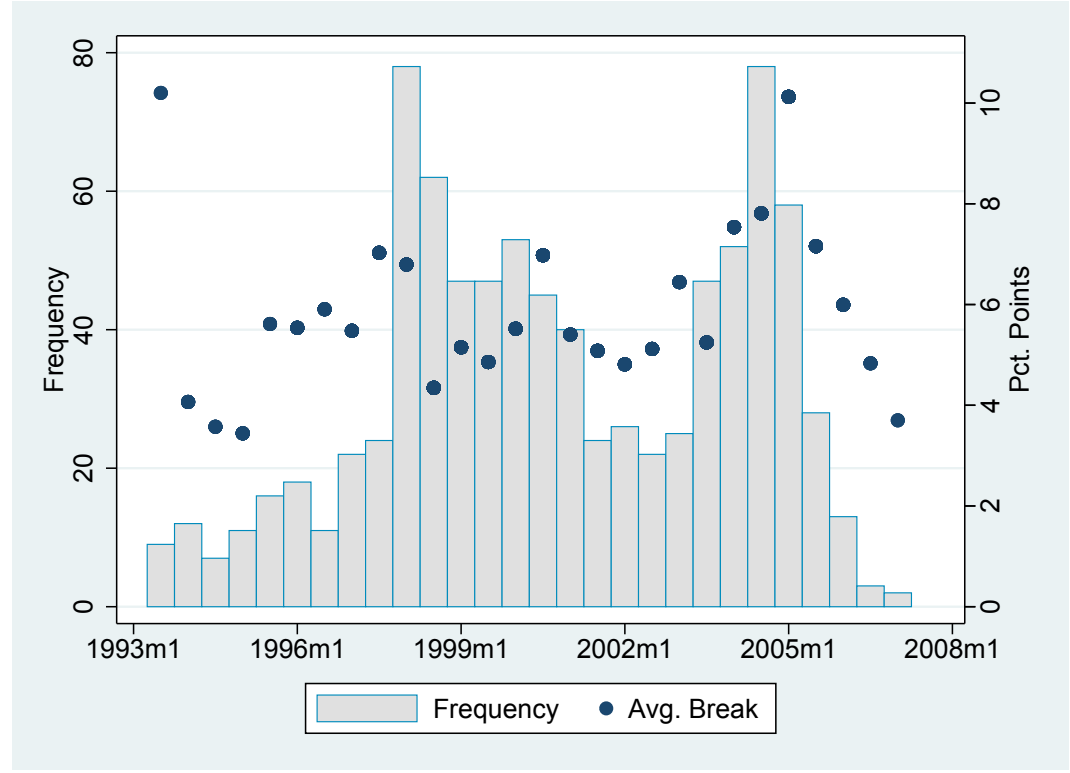

(b) Second House Price Break

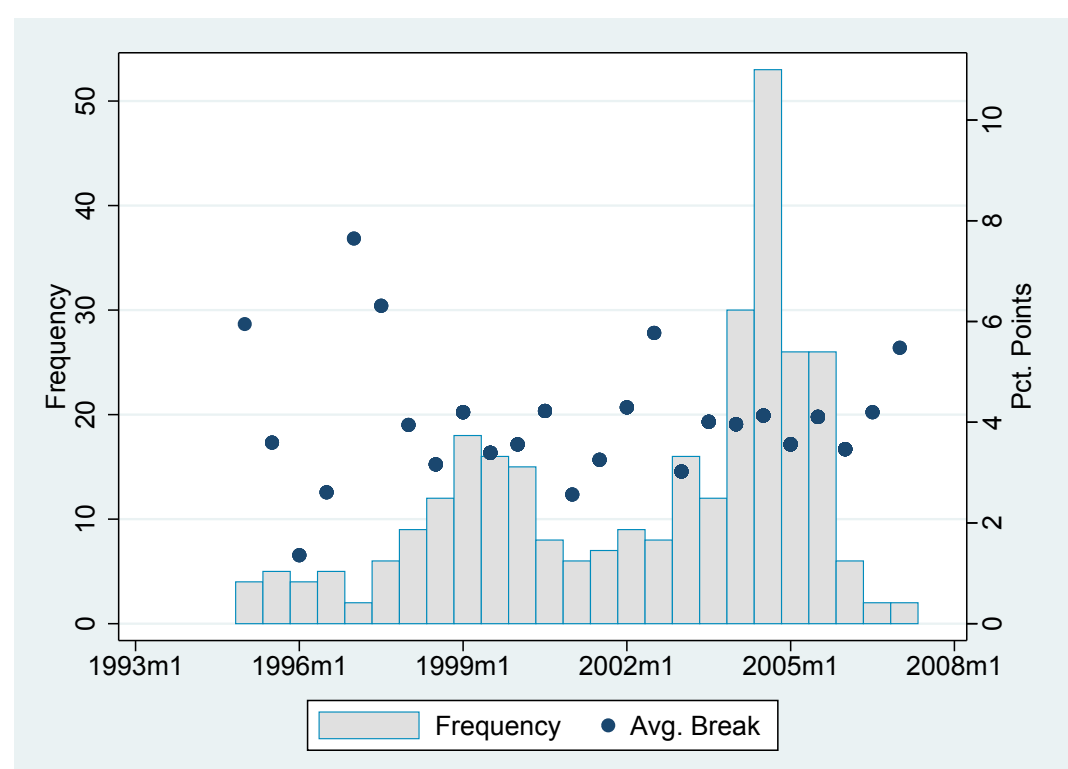

Note: 984 counties have a valid first house price break. 452 counties have a valid second house price break. The magnitude of house price break is calculated as $H P A_{t+11}-H P A_{t-1}$, where $t$ is a month of the first house price break. 
Figure 6: House Price Breaks by Early and Late Counties

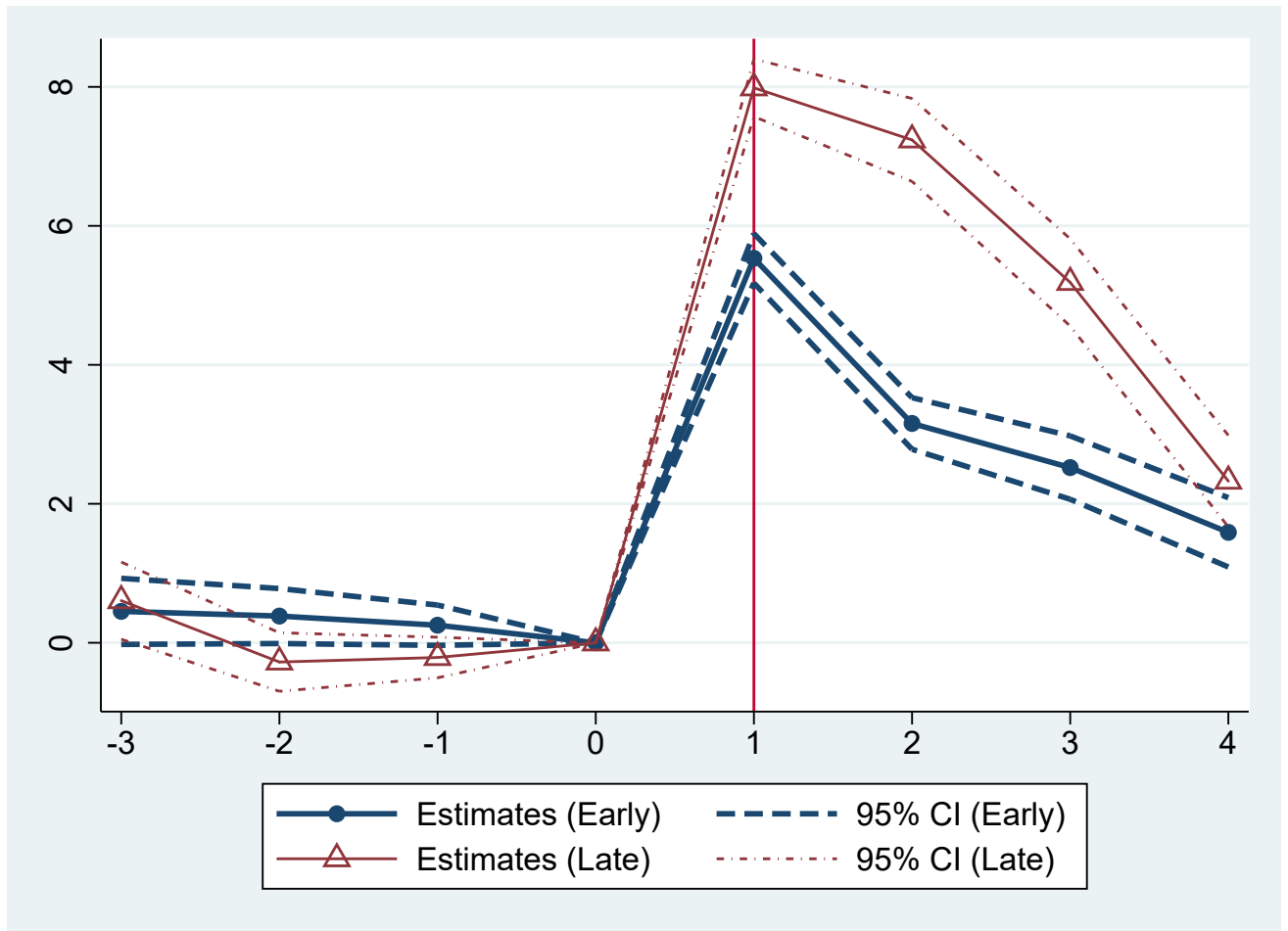

Note: The figure shows event study figures for the 12-month house price appreciation where where time $=0$ is the year of the structural break in house prices. See text for details of break-point methodology. "Early" counties are defined to have the first house break before January 2000 and "late" counties have the break in January 2000 or later. Dashed lines represent 95 percent confidence intervals. Event study specifications include county fixed effects, a quadratic in calendar time and economic fundamentals (income and unemployment). See text for details on event study methodology. 
Figure 7: First and Second House Price Breaks

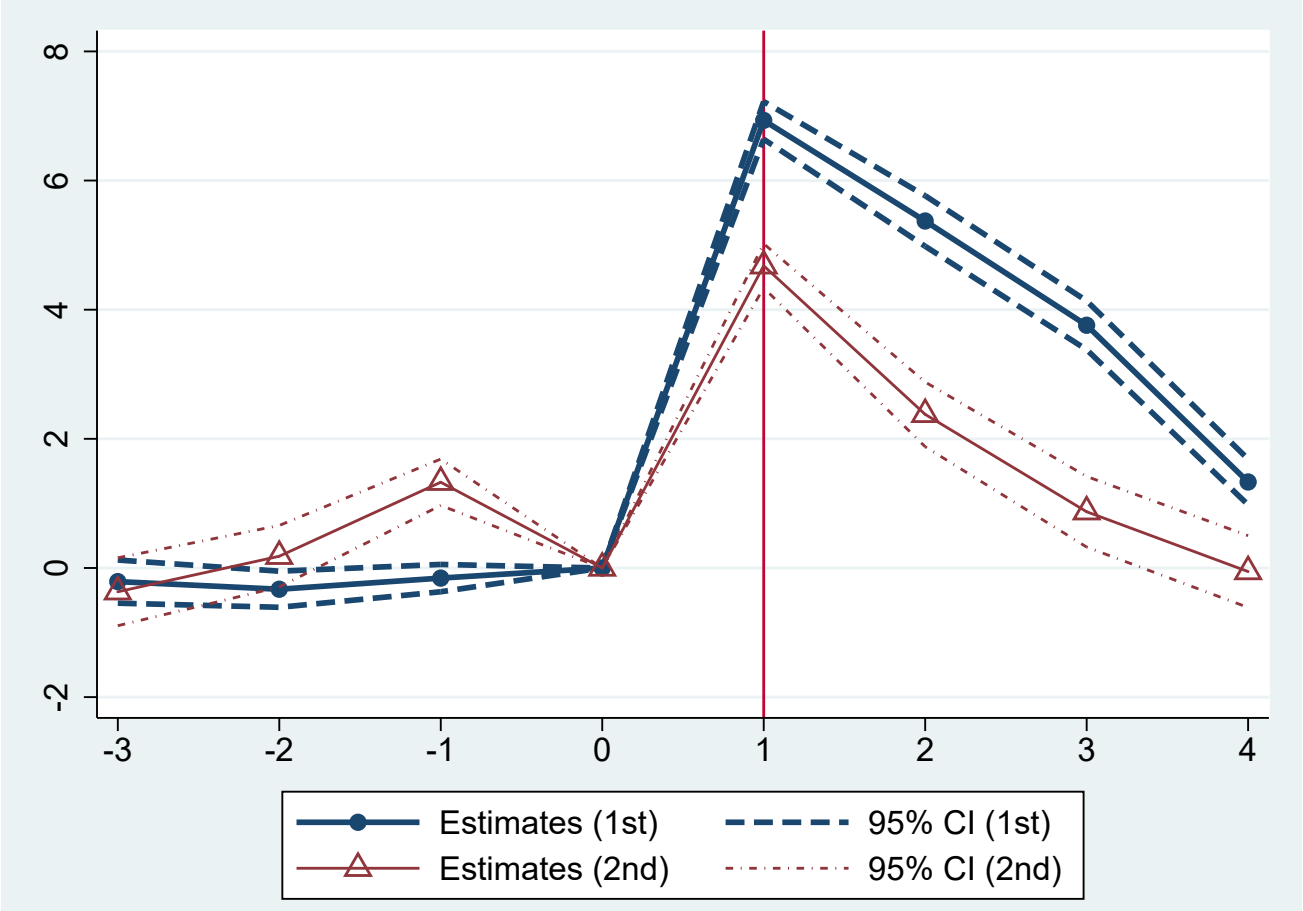

Note: Counties are defined to have a valid first break if the corresponding break is statistically significant at $95 \%$ and have at least 36 months between January 1993 and the month of peak HPA. Similarly, counties are defined to have a valid second break if the corresponding break is statistically significant at the $95 \%$ and have at least 12 months between the first peak and the second peak. Among 1,163 in-sample counties, 984 have a valid first house break and 452 have a valid second house break. 
Figure 8: Non-traditional Mortgages by Early and Late Counties
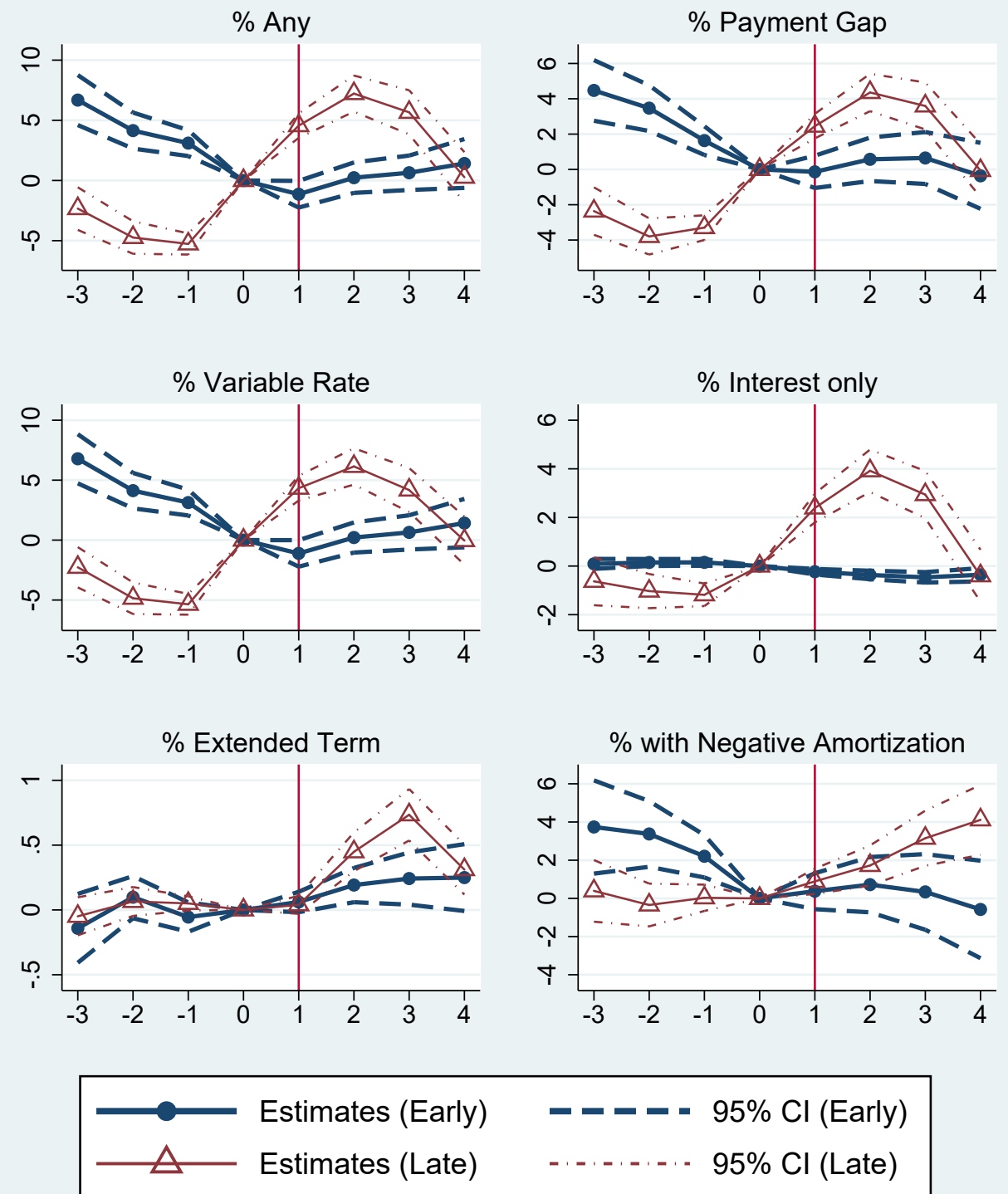

Note: The figure shows the event study figures for alternative financing variables where where time $=0$ is the year of the structural break in house prices. See text for details of break-point methodology. "Early" counties have the first house break before January 2000 and "late" counties have the first break in January 2000 or later. Dashed lines represent 95 percent confidence intervals. Event study specification include county fixed effects, a quadratic in calendar time and economic fundamentals (income and unemployment). See text for details on event study methodology. 
Figure 9: Non-traditional Mortgages around First and Second House Price Breaks
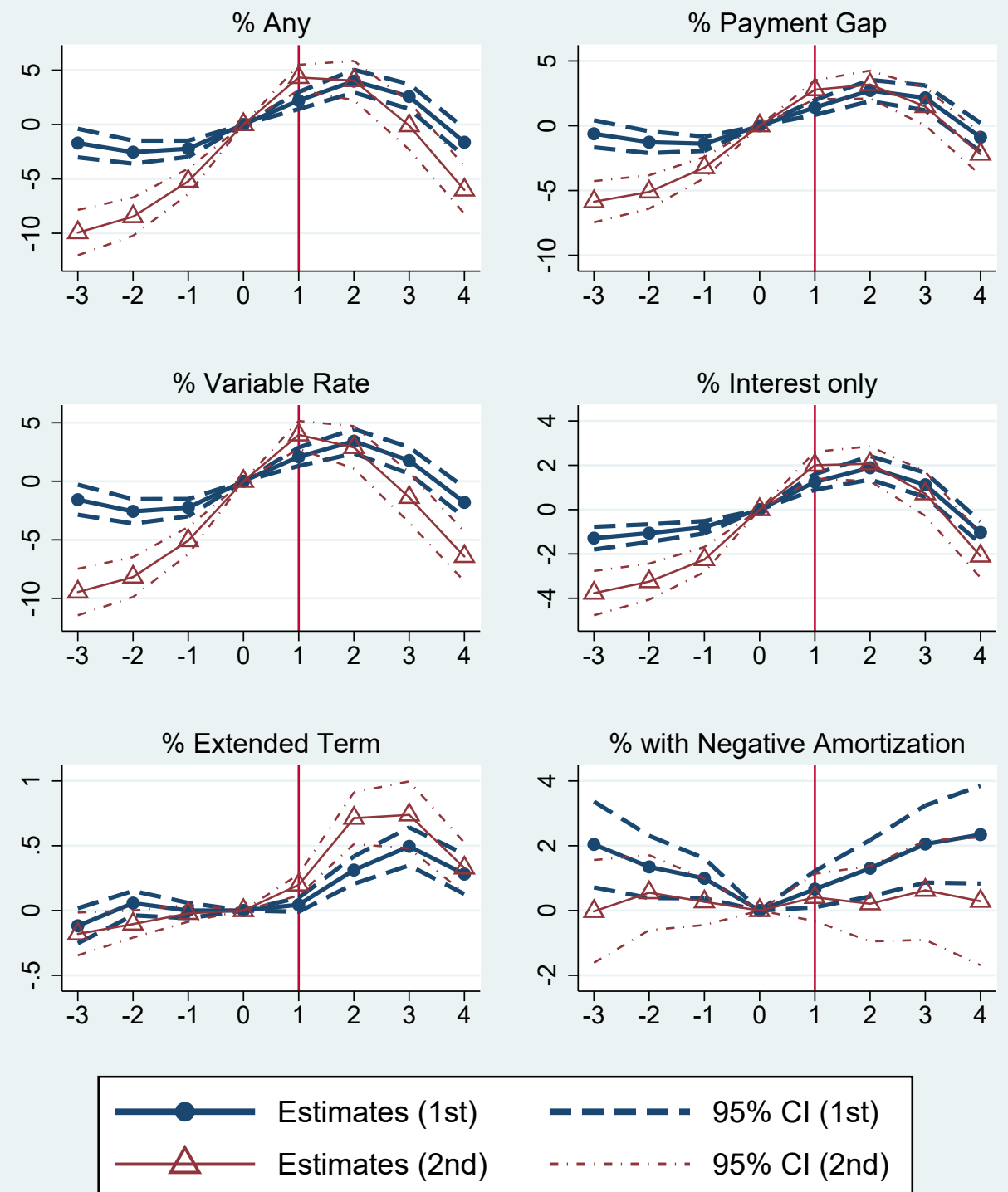

Note: The figure shows the event study figures for alternative financing variables where time $=0$ is the year of the first and second structural break in house prices, respectively. See text for details of break-point methodology. Dashed lines represent 95 percent confidence intervals. Event study specification include county fixed effects, a quadratic in calendar time and economic fundamentals (income and unemployment). See text for details on event study methodology. 
Figure 10: Economic Fundamentals by Early and Late Counties

(a) Income $\$ 1000$

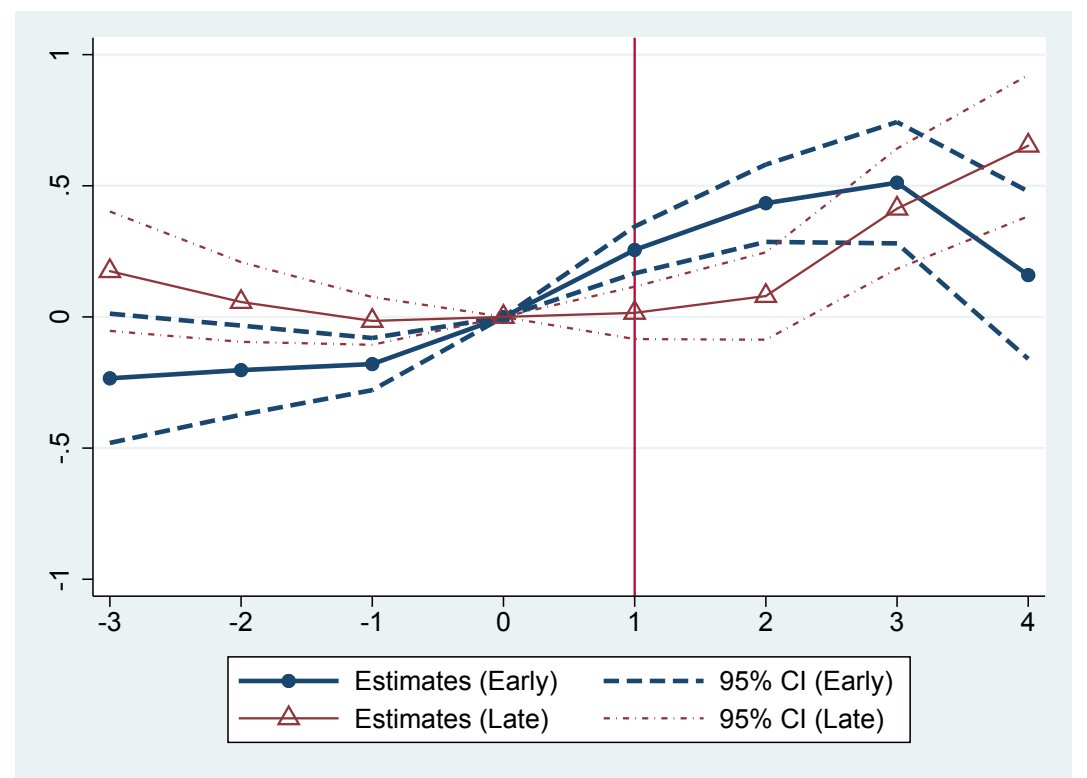

(b) Unemployment Rate $\%$

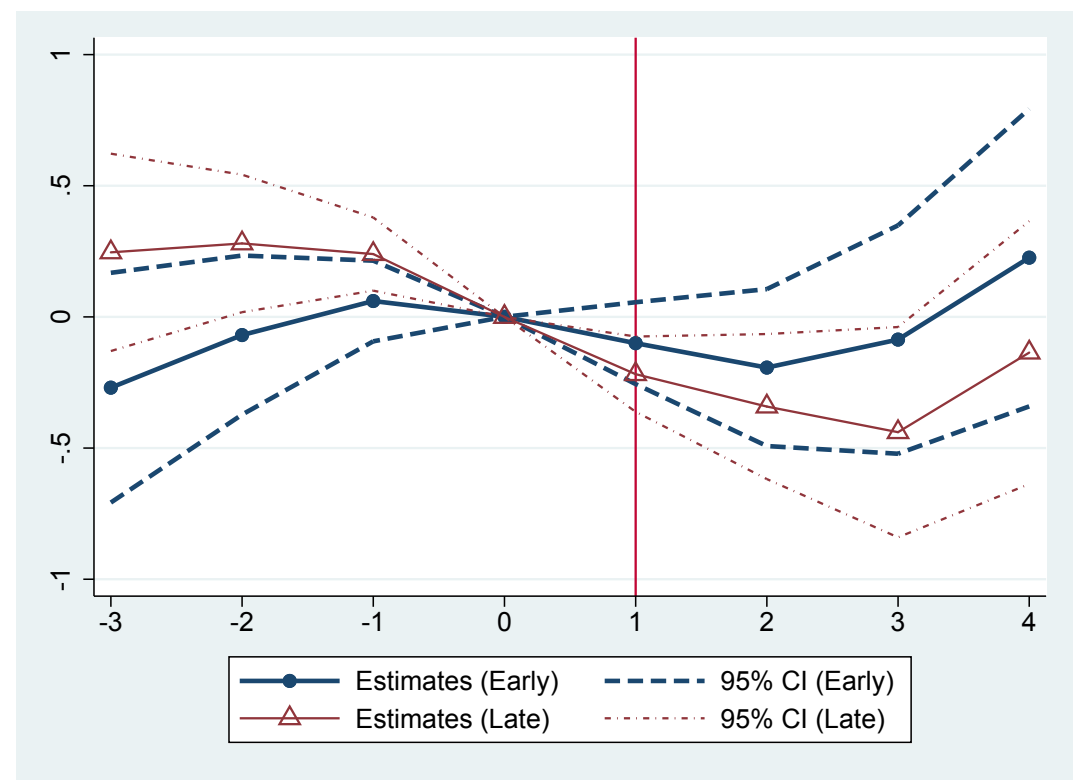

Note: The figure shows the event study figures for economic fundamentals (income and unemployment rate) where time $=0$ is the year of the structural break in house prices. See text for details of break-point methodology. "Early" counties have their first house break before January 2000 and "late" counties have their first break in January 2000 or later. Dashed lines represents 95 percent confidence intervals. Event study specification include county fixed effects, and a quadratic in calendar time. See text for details on event study methodology. 
Figure 11: Mortgage Attributes by Early and Late Counties
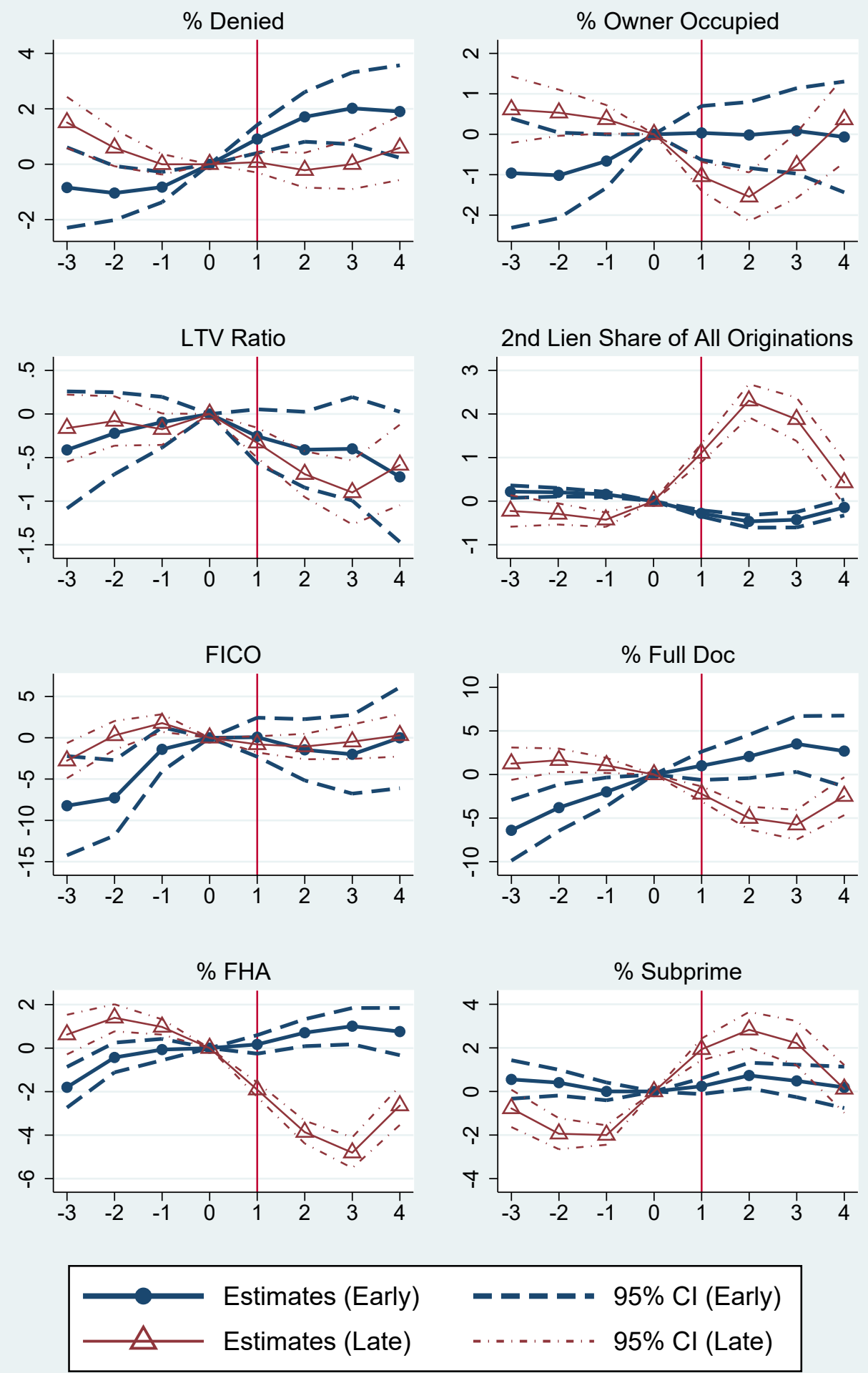

Note: The figure shows the event study figures for mortgage variables where time $=0$ is the year of the structural break in house prices. See text for details of break-point methodology. "Early" counties have the first house break before January 2000 and "late" counties have the first break in January 2000 or later. Dashed lines represent 95 percent confidence intervals. Event study specification include county fixed effects, a quadratic in calendar time and economic fundamentals (income and unemployment). See text for details on event study methodology. 
Figure 12: Appreciation and Alternative Finance by Non-Core Lending Quartile

(a) House Price Appreciation

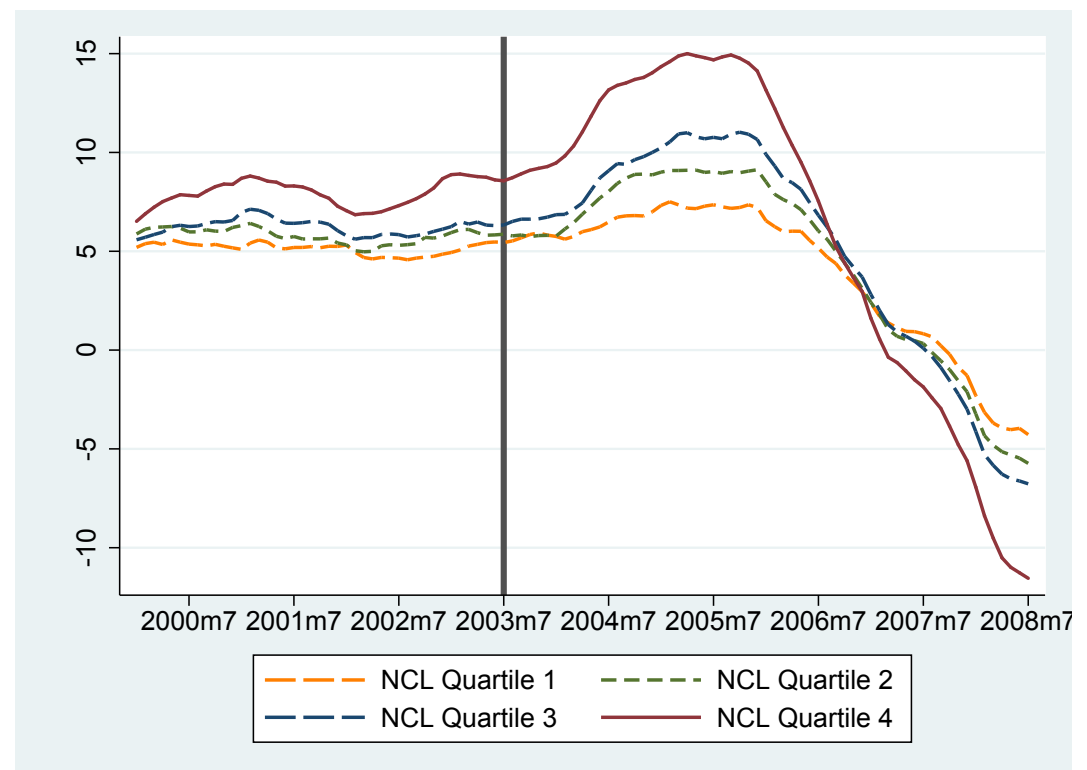

(b) \% Any

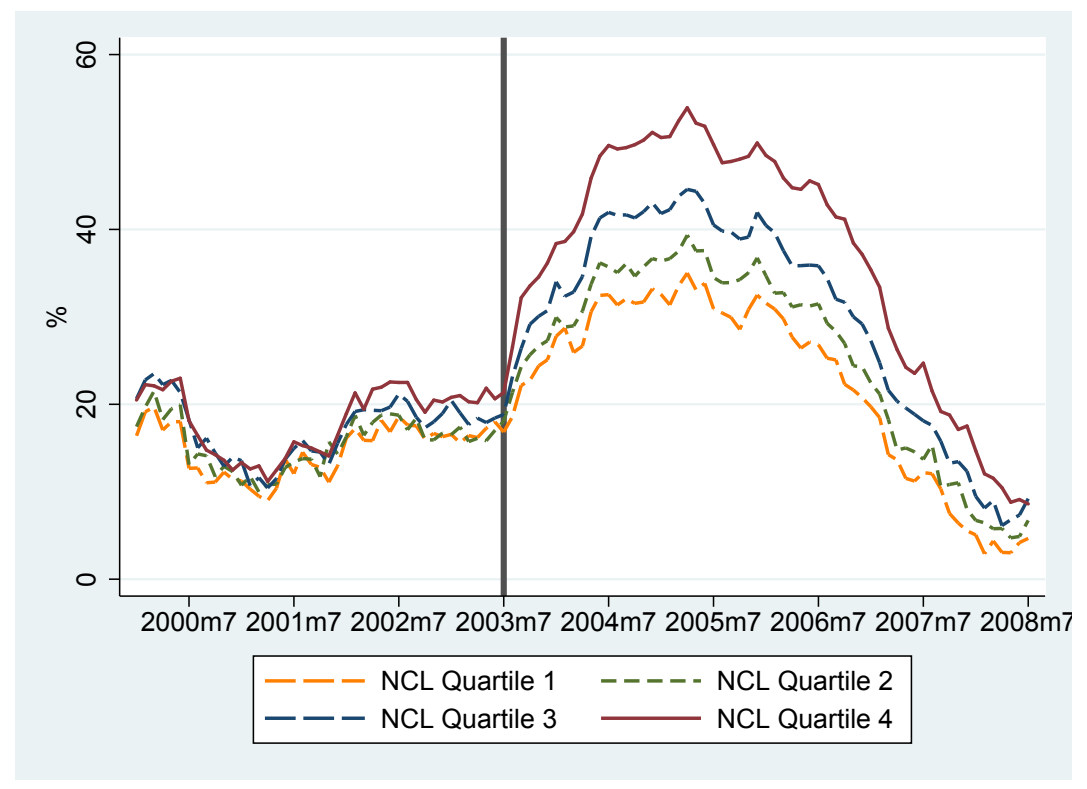

Note: This figure shows use of alternative mortgage products and house price appreciation around the mid-2003 acceleration of the private label securities market. Counties are divided into quartiles by their mortgage-making lenders' share of non-core deposits in 2002 as in Mian and Sufi (2018), dollar-weighted by the value of mortgages originated in the county in 2002. Both house price appreciation (measured here by year over year HPI) and the use of alternative mortgage products increase with the share of non-core lending monotonically, with the growth in alternative products preceding the largest growth in house prices. 
Figure 13: Non-Traditional Mortgage Features by Non-Core Lending Quartile
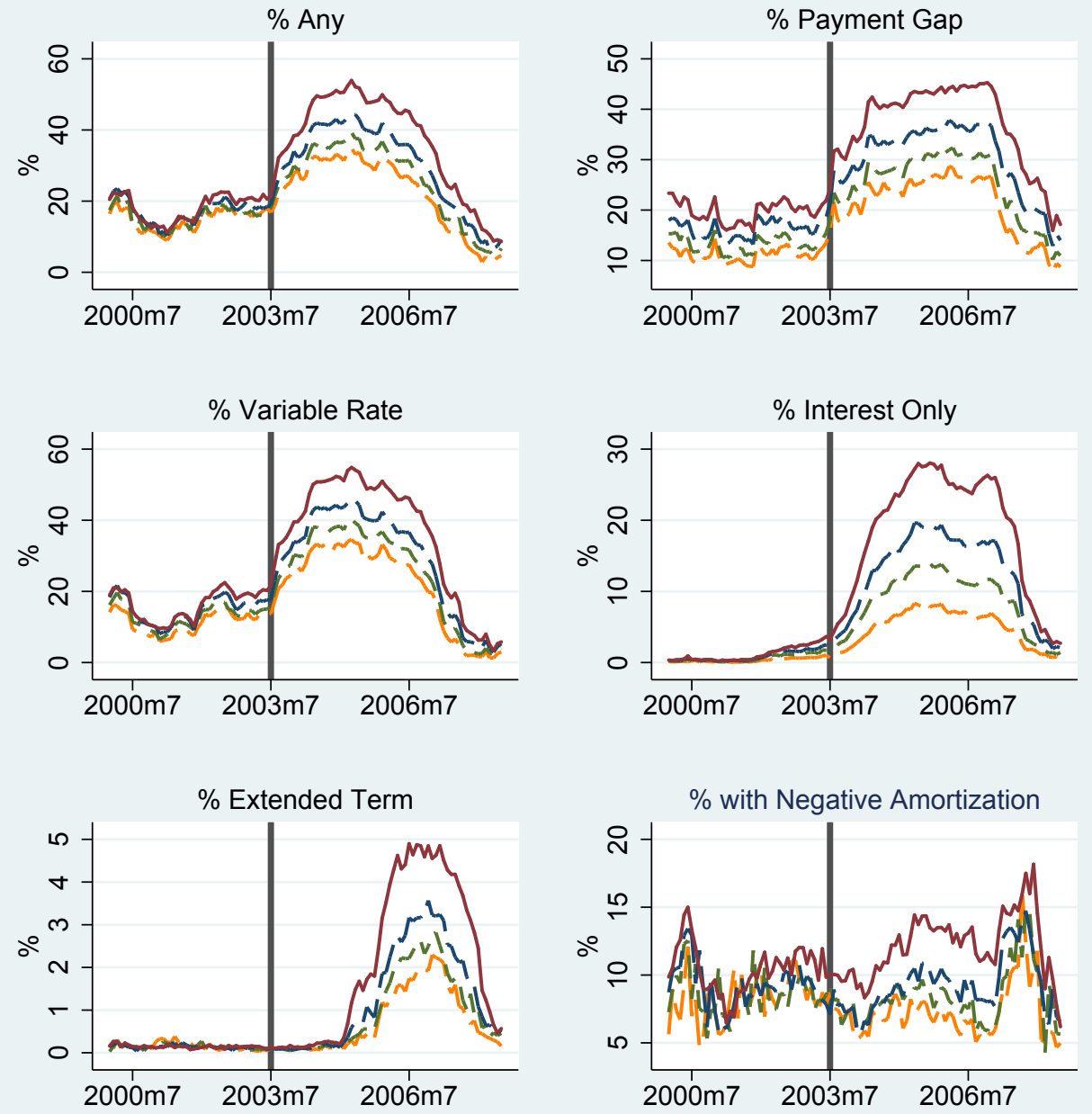

Note: This figure shows use of alternative mortgage features around the mid-2003 acceleration of the private label securities market. Counties are divided into quartiles by their mortgage-making lenders' share of non-core deposits in 2002 as in Mian and Sufi (2018), dollar-weighted by the value of mortgages originated in the county in 2002. Variable rate share responds most immediately to the credit supply shock in high-NCL counties, with I/O and then extended term mortgages responding subsequently and differentially across quartile. 
Figure 14: Mortgage Attributes by Non-Core Lending Quartile
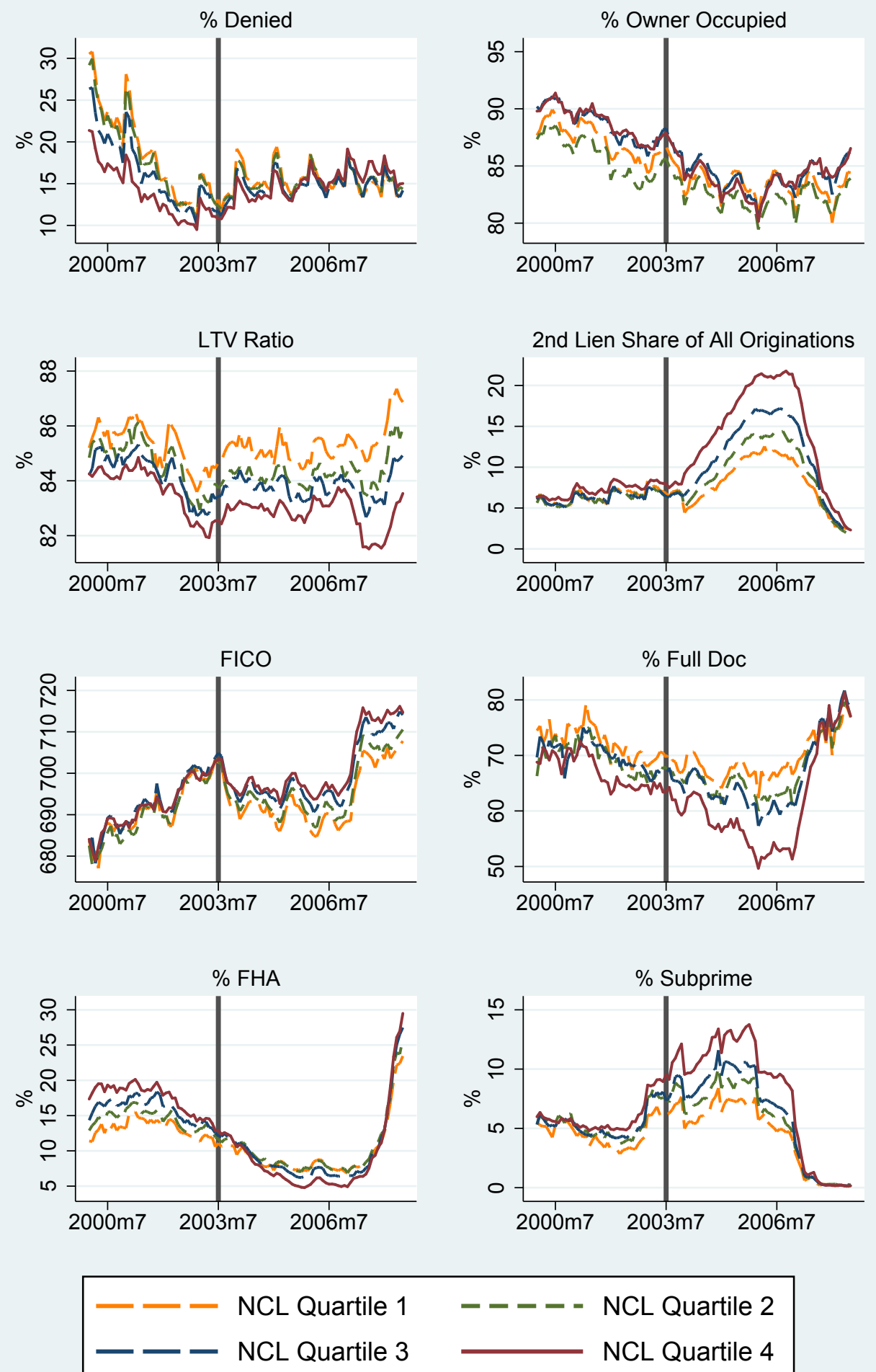

Note: This figure shows patterns in mortgage attributes around the mid-2003 acceleration of the private label securities market. Counties are divided into quartiles by their mortgage-making lenders' share of non-core deposits in 2002 as in Mian and Sufi (2018), dollar-weighted by the value of mortgages originated in the county in 2002. High-NCL counties show a sharp increase in subprime share and full documentation, with subsequent growth in the prevalence of second liens, relative to other quartiles that are less dependent on the securitization channel of origination. 
Table 1: Summary Statistics for Pooled Sample of Counties

\begin{tabular}{lccc}
\hline \hline & Overall & Early & Late \\
& $(1)$ & $(2)$ & $(3)$ \\
\hline HPA & 8.5 & 6.7 & 9.7 \\
& $(6.2)$ & $(4.6)$ & $(6.9)$ \\
\hline \% Any & 19.4 & 11.5 & 24.8 \\
& $(15.9)$ & $(9.6)$ & $(17.0)$ \\
\% Payment Gap & 18.2 & 11.8 & 22.5 \\
& $(13.7)$ & $(10.5)$ & $(14.0)$ \\
\% Variable Rate & 18.9 & 11.3 & 24.1 \\
& $(15.3)$ & $(9.5)$ & $(16.2)$ \\
\% Interest Only & 3.6 & 0.2 & 5.9 \\
& $(8.1)$ & $(1.2)$ & $(9.9)$ \\
\% Extended Term & 0.2 & 0.2 & 0.2 \\
& $(0.9)$ & $(1.0)$ & $(0.8)$ \\
\% Negative Amortization & 7.6 & 5.6 & 9.1 \\
& $(11.0)$ & $(11.4)$ & $(10.5)$ \\
\hline \% Denied & 15.3 & 17.6 & 13.6 \\
& $(8.8)$ & $(10.9)$ & $(6.5)$ \\
\% Owner Occupied & 87.1 & 91.5 & 84.2 \\
LTV Ratio & $(11.2)$ & $(8.4)$ & $(11.9)$ \\
\% FHA Subprime & 84.0 & 83.5 & 84.2 \\
& $(4.5)$ & $(5.0)$ & $(4.1)$ \\
FICO Lien Share of All Originations & 2.2 & 0.3 & 3.6 \\
& $(3.4)$ & $(0.9)$ & $(3.8)$ \\
Uncome (\$1000) & 694.1 & 692.9 & 694.8 \\
& $(25.7)$ & $(32.2)$ & $(19.9)$ \\
& 69.0 & 71.4 & 67.4 \\
& $(18.4)$ & $(21.9)$ & $(15.3)$ \\
& 14.1 & 15.8 & 12.9 \\
& $(9.2)$ & $(9.5)$ & $(8.8)$ \\
& 10.4 & 5.1 & 14.0 \\
& $(8.8)$ & $(4.9)$ & $(9.0)$ \\
\hline
\end{tabular}

Note: The table presents summary statistics for all counties with an estimated structural break in house prices. Values are countymonth averages, with standard deviations in parentheses. Sample consists of county-months in the year before and after the county experiences a house price break. Source: Authors' calculations using HMDA, LPS Applied Analytics, Bureau of Labor Statistics, and CoreLogic data. 
Table 2: House Price Growth Rate around County-Specific Structural Break Points

(a) First House Price Break

\begin{tabular}{lcccccc}
\hline \hline & \multicolumn{2}{c}{ Overall } & \multicolumn{2}{c}{ Early } & \multicolumn{2}{c}{ Late } \\
& $(1)$ & $(2)$ & $(3)$ & $(4)$ & $(5)$ & $(6)$ \\
\hline House Price Growth & 7.12 & 6.93 & 6.23 & 5.53 & 7.84 & 7.99 \\
& $(0.13)$ & $(0.15)$ & $(0.17)$ & $(0.18)$ & $(0.18)$ & $(0.21)$ \\
\hline County FE? & $\mathrm{Y}$ & $\mathrm{Y}$ & $\mathrm{Y}$ & $\mathrm{Y}$ & $\mathrm{Y}$ & $\mathrm{Y}$ \\
Calendar Time Controls? & $\mathrm{N}$ & $\mathrm{Y}$ & $\mathrm{N}$ & $\mathrm{Y}$ & $\mathrm{N}$ & $\mathrm{Y}$ \\
Econ Fundamentals? & $\mathrm{N}$ & $\mathrm{Y}$ & $\mathrm{N}$ & $\mathrm{Y}$ & $\mathrm{N}$ & $\mathrm{Y}$ \\
\hline Within R-sq. & 0.25 & 0.28 & 0.33 & 0.39 & 0.26 & 0.36 \\
No. Obs & 92092 & 92092 & 39419 & 39419 & 52673 & 52673 \\
No. County & 984 & 984 & 434 & 434 & 550 & 550 \\
\hline \hline
\end{tabular}

(b) Second House Price Break

\begin{tabular}{lcccccccc}
\hline \hline & \multicolumn{2}{c}{ With 2nd Break } & \multicolumn{2}{c}{ With Both Breaks } & \multicolumn{2}{c}{ Early } & \multicolumn{2}{c}{ Late } \\
& $(1)$ & $(2)$ & $(3)$ & $(4)$ & $(5)$ & $(6)$ & $(7)$ & $(8)$ \\
\hline House Price Growth & 3.91 & 4.68 & 3.79 & 4.76 & 4.07 & 5.03 & 3.13 & 4.18 \\
& $(0.16)$ & $(0.17)$ & $(0.20)$ & $(0.21)$ & $(0.22)$ & $(0.24)$ & $(0.41)$ & $(0.43)$ \\
\hline County FE? & $\mathrm{Y}$ & $\mathrm{Y}$ & $\mathrm{Y}$ & $\mathrm{Y}$ & $\mathrm{Y}$ & $\mathrm{Y}$ & $\mathrm{Y}$ & $\mathrm{Y}$ \\
Calendar Time Controls? & $\mathrm{N}$ & $\mathrm{Y}$ & $\mathrm{N}$ & $\mathrm{Y}$ & $\mathrm{N}$ & $\mathrm{Y}$ & $\mathrm{N}$ & $\mathrm{Y}$ \\
Econ Fundamentals? & $\mathrm{N}$ & $\mathrm{Y}$ & $\mathrm{N}$ & $\mathrm{Y}$ & $\mathrm{N}$ & $\mathrm{Y}$ & $\mathrm{N}$ & $\mathrm{Y}$ \\
\hline Within R-sq. & 0.21 & 0.29 & 0.27 & 0.35 & 0.26 & 0.34 & 0.32 & 0.40 \\
No. Obs & 42790 & 42790 & 31523 & 31523 & 22090 & 22090 & 9433 & 9433 \\
No. County & 452 & 452 & 330 & 330 & 231 & 231 & 99 & 99 \\
\hline \hline
\end{tabular}

Note: The table presents coefficients from an event study regression of the change in house prices around the timing of the estimated structural break in house prices. Estimates are the percentage point difference in the annual growth rate of house prices in year of the house price break relative to the previous year. Quadratic controls for calendar time used. Odd number columns show the results with no economic controls and even number columns show those with the economic controls, income level and unemployment rate. Income as a response variable is only controlled for unemployment rate, and vice versa. "Early" signifies counties with its first house price break prior to 2000. Among the 1,163 sample counties, 452 counties have the second house breaks and only 330 counties have both breaks. Standard errors clustered at the county level are in parentheses. In the second panel, we categorizes counties early or late only if they have both breaks. Source: Authors' calculations using CoreLogic data. 
Table 3: Structural Breaks in Non-traditional Mortgages Relative to House Price Structural Breaks

(a) Counties with First Break before January 2000 (“Early”)

\begin{tabular}{lcccc}
\hline \hline & \multicolumn{3}{c}{ With Respect to House Price Break } & Share \\
\cline { 2 - 4 } & $\begin{array}{c}\text { Before } \\
\text { Estimated }\end{array}$ & Same & After & $(4)$ \\
\hline Any Break & 4.38 & $(2)$ & $(3)$ & 42.86 \\
Payment Gap Break & 6.68 & 1.15 & 24.42 & 32.26 \\
Variable Rate Break & 4.15 & 0.23 & 35.71 & 40.09 \\
Interest Only Break & 1.61 & 0.23 & 73.73 & 75.58 \\
Extended Term Break & 2.07 & 0.69 & 47.47 & 50.23 \\
Negative Amortization Break & 10.37 & 0.46 & 30.81 & 41.01 \\
\hline \hline
\end{tabular}

(b) Counties with First Break in January 2000 and after ("Late")

\begin{tabular}{lcccc}
\hline \hline & \multicolumn{3}{c}{ With Respect to House Price Break } & Share \\
\cline { 2 - 4 } & $\begin{array}{c}\text { Before } \\
\text { Estimated }\end{array}$ & Same & After & $(4)$ \\
\hline Any Break & 13.64 & $(2)$ & $(3)$ & 34.36 \\
Payment Gap Break & 14.91 & 3.82 & 9.27 & 28.00 \\
Variable Rate Break & 13.45 & 2.18 & 16.55 & 32.18 \\
Interest Only Break & 16.00 & 10.55 & 44.18 & 70.73 \\
Extended Term Break & 6.55 & 0.91 & 42.91 & 50.36 \\
Negative Amortization Break & 27.09 & 0.73 & 13.27 & 41.09 \\
\hline \hline
\end{tabular}

Note: The tables show whether structural breaks in non-traditional mortgage variables occur before, concurrently, or after first or second estimated structural breaks in house prices in a given county. The break is defined to occur "before" if (difference) $<3$, "concurrently" if $-3<$ (difference) $<3$, and "after" if (difference) $>3$. First three columns do not necessarily sum to 100 percent in a given row because counties do not always have an estimated break in other variables. "Share Estimated" represents the total share of counties with a house price break (early or late, respectively) that also had a break in the given non-traditional mortgage variable. Sample consists of counties experiencing each house price break. Source: Authors' calculations using HMDA, LPS Applied Analytics, Bureau of Labor Statistics, and CoreLogic data. 
Figure A.1: Share of New Originations with Alternative Financing Features
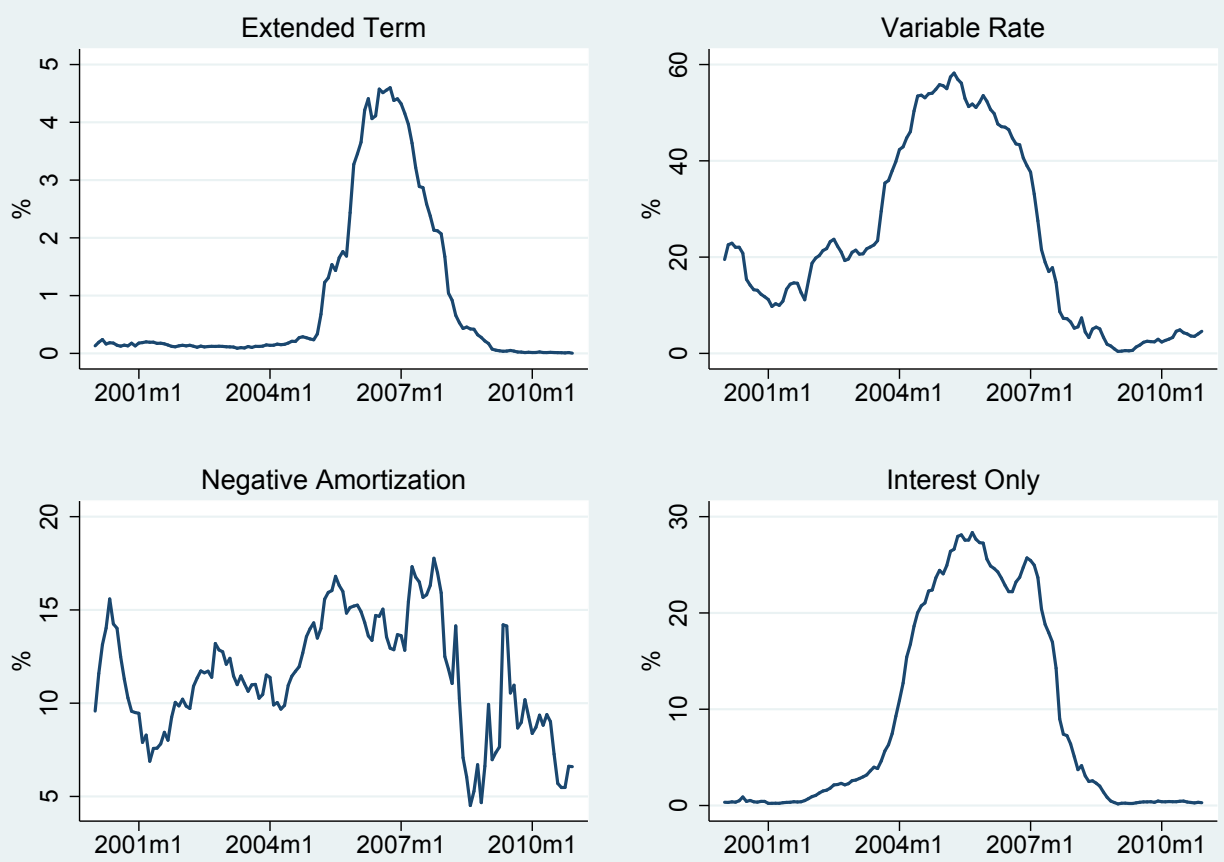

Note: The figure shows the time series of the fraction of purchase loans with each of four alternative financing features: extended term (top left), variable rate (top right), negatively amortizing contract (bottom left), and interest-only contract (bottom right). See text for additional details. 
Figure A.2: Equilibrium House Price in the Second Period

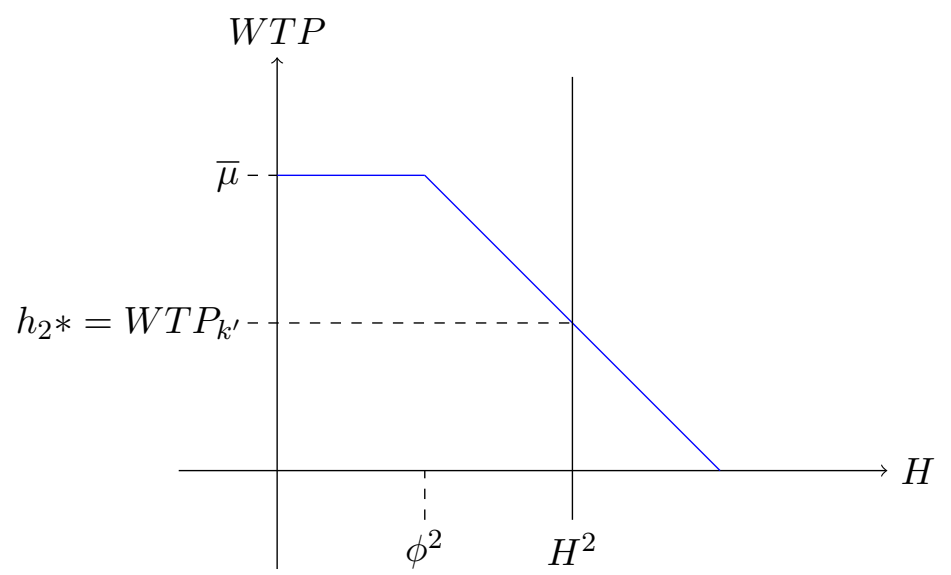

Note: This figure shows how the equilibrium house price is derived from the intersection of the inelastic housing supply curve, $H^{2}$, and the schedule of the willingness to pay of the second generation consumers, WTP. 
Figure A.3: Sample Counties with Both First and Second House Price Break
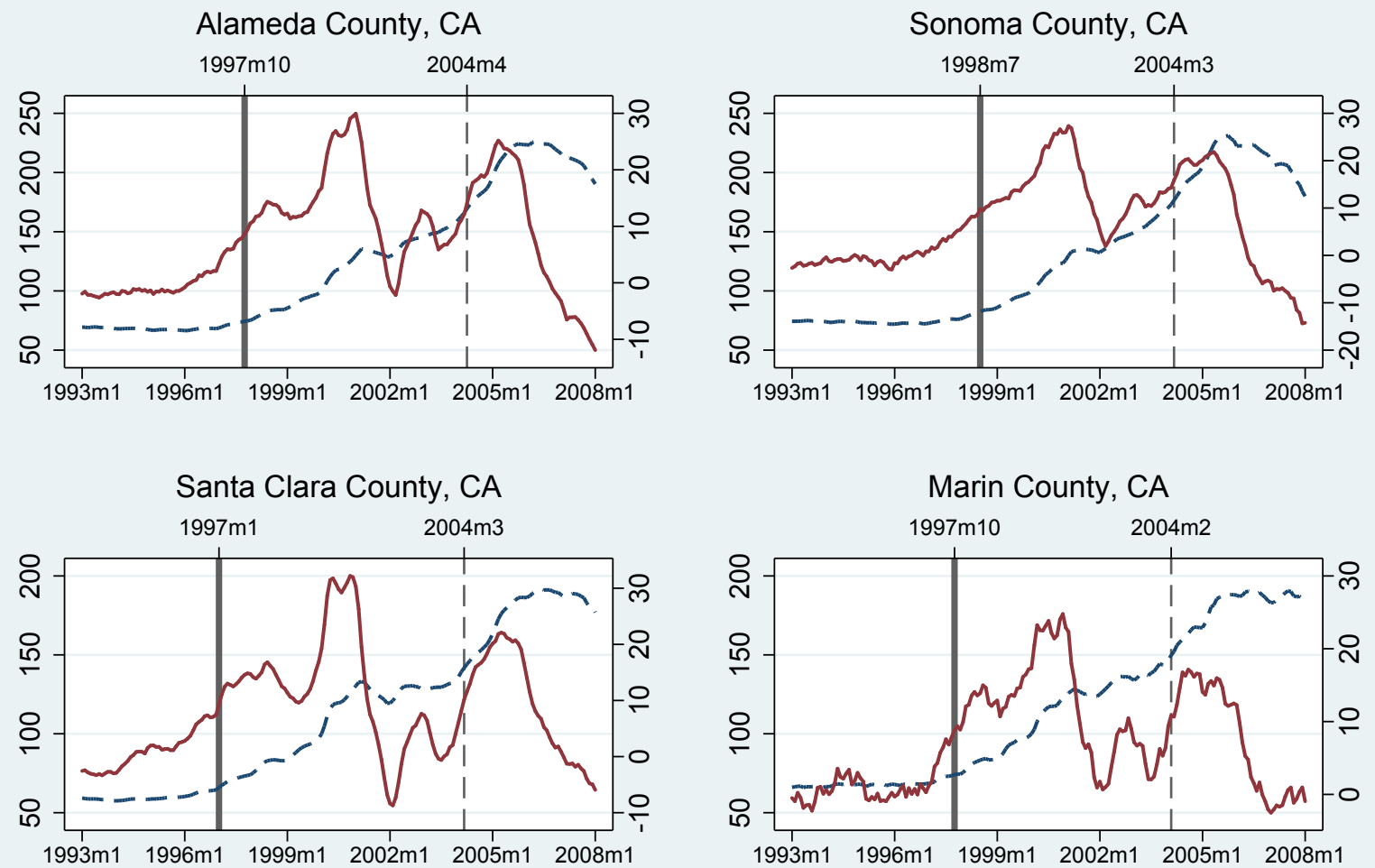

House Price Index $(\operatorname{Jan} 2000=100)$

12-Month Appreciation

Note: The figure shows the timing of structural house price breaks in four counties with two house price breaks: Alameda County (top left), Sonoma County (top right), Santa Clara County (bottom left), and Marin County (bottom right), all in California. Structural breaks estimated using break-point methodology described in the text. Each panel shows both the house price index (blue dashed line) and 12-month appreciation rate (solid red line). 
Figure A.4: Non-traditional Mortgages around First House Price Breaks
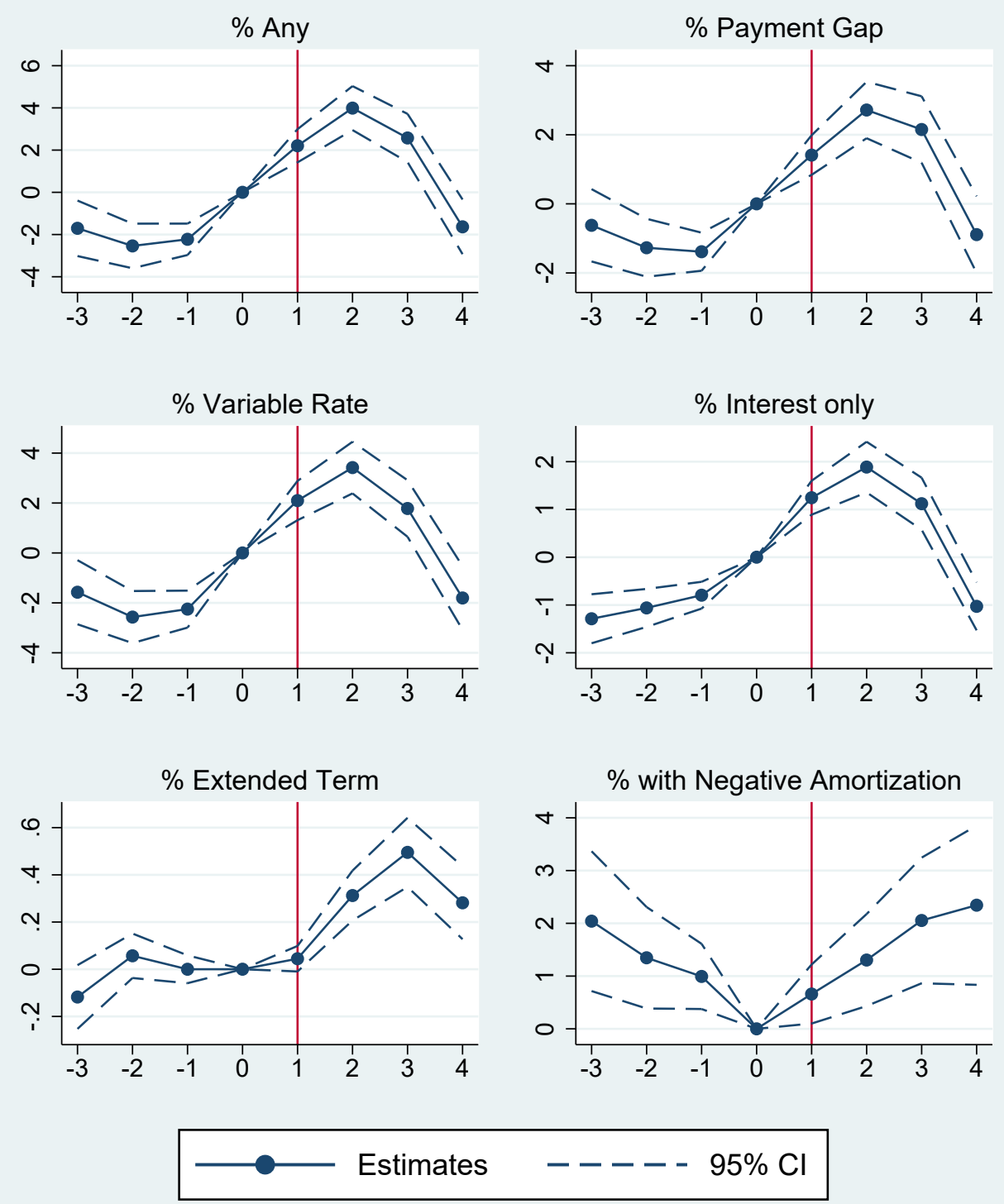

Note: The figure shows the event study figures for alternative financing variables where time $=0$ is the year of the first structural break in house prices. See text for details of break-point methodology. Dashed lines represent 95 percent confidence intervals. Event study specification include county fixed effects, a quadratic in calendar time and economic fundamentals (income and unemployment). See text for details on event study methodology. 
Figure A.5: Mortgage Attributes around First House Price Breaks
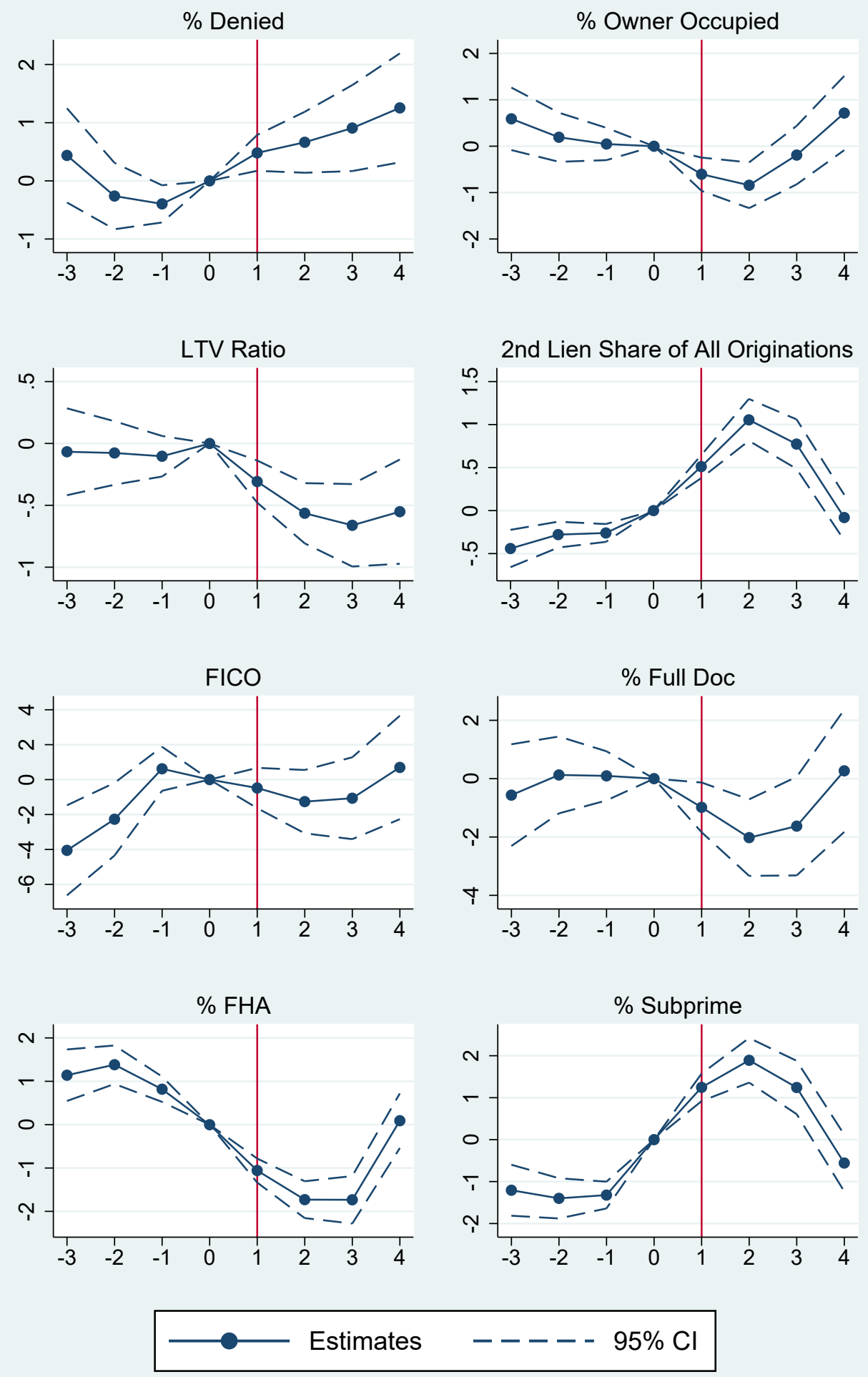

Note: The figure shows the event study figures for mortgage variables where time $=0$ is the year of the structural break in house prices. See text for details of break-point methodology. Dashed lines represent 95 percent confidence intervals. Event study specification include county fixed effects, a quadratic in calendar time and economic fundamentals (income and unemployment). See text for details on event study methodology. 
Table A.1: Summary Statistics for Year Prior to the First House Price Break

\begin{tabular}{lccc}
\hline \hline & Overall & Early & Late \\
& $(1)$ & $(2)$ & $(3)$ \\
\hline HPA & 5.3 & 4.0 & 6.1 \\
& $(4.0)$ & $(3.3)$ & $(4.2)$ \\
\hline \% Any & 17.7 & 11.6 & 21.8 \\
& $(14.2)$ & $(9.8)$ & $(15.1)$ \\
\% with Payment Gap & 16.8 & 11.2 & 20.5 \\
& $(12.9)$ & $(10.3)$ & $(13.1)$ \\
\% Variable Rate & 17.5 & 11.4 & 21.5 \\
& $(13.9)$ & $(9.7)$ & $(14.8)$ \\
\% Interest Only & 2.5 & 0.3 & 4.0 \\
& $(6.2)$ & $(1.4)$ & $(7.6)$ \\
\% Extended Term & 0.2 & 0.2 & 0.1 \\
& $(0.9)$ & $(1.2)$ & $(0.6)$ \\
\% Negative Amortization & 7.5 & 5.4 & 8.9 \\
& $(11.2)$ & $(11.3)$ & $(10.8)$ \\
\hline \% Denied & 15.2 & 17.3 & 13.8 \\
& $(8.9)$ & $(10.9)$ & $(6.9)$ \\
\% Owner Occupied & 87.7 & 91.6 & 85.2 \\
& $(10.7)$ & $(8.3)$ & $(11.4)$ \\
LTV Ratio & 84.0 & 83.4 & 84.5 \\
\% FHA & $(4.6)$ & $(5.1)$ & $(4.1)$ \\
FICO & 1.8 & 0.3 & 2.8 \\
& $(3.0)$ & $(0.8)$ & $(3.4)$ \\
Income (in 1000s) & 694.1 & 693.5 & 694.5 \\
& $(26.5)$ & $(33.9)$ & $(20.2)$ \\
& 69.5 & 71.3 & 68.4 \\
& $(18.9)$ & $(22.7)$ & $(15.8)$ \\
& 14.9 & 15.9 & 14.2 \\
& $(9.3)$ & $(9.6)$ & $(9.1)$ \\
& 9.4 & 4.3 & 12.7 \\
& $(8.3)$ & $(4.5)$ & $(8.5)$ \\
\hline \hline
\end{tabular}

Note: The table presents summary statistics for all counties with an estimated structural break in house prices. Values are countymonth averages, with standard deviations in parentheses. Sample consists of county-months in the prior year of the county's house price break. 
Table A.2: Non-traditional Mortgages around House Price Structural Breaks

\begin{tabular}{lcccccc}
\hline \hline & \multicolumn{2}{c}{ Overall } & \multicolumn{2}{c}{ Early } & \multicolumn{2}{c}{ Late } \\
& $(1)$ & $(2)$ & $(3)$ & $(4)$ & $(5)$ & $(6)$ \\
\hline \% Any & 3.12 & 2.21 & -0.67 & -1.14 & 6.29 & 4.56 \\
& $(0.37)$ & $(0.40)$ & $(0.52)$ & $(0.57)$ & $(0.46)$ & $(0.52)$ \\
\% with Payment Gap & 2.62 & 1.41 & 0.89 & -0.14 & 4.05 & 2.45 \\
& $(0.25)$ & $(0.29)$ & $(0.38)$ & $(0.47)$ & $(0.32)$ & $(0.35)$ \\
\% Variable Rate & 2.81 & 2.10 & -0.60 & -1.11 & 5.66 & 4.33 \\
& $(0.37)$ & $(0.40)$ & $(0.52)$ & $(0.56)$ & $(0.46)$ & $(0.53)$ \\
\% Interest Only & 2.09 & 1.25 & -0.04 & -0.23 & 3.84 & 2.39 \\
& $(0.18)$ & $(0.18)$ & $(0.04)$ & $(0.06)$ & $(0.30)$ & $(0.30)$ \\
\% Extended Term & 0.07 & 0.04 & -0.09 & 0.06 & 0.19 & 0.04 \\
& $(0.02)$ & $(0.03)$ & $(0.03)$ & $(0.04)$ & $(0.03)$ & $(0.04)$ \\
\% Negative Amortization & 0.42 & 0.66 & 0.30 & 0.38 & 0.52 & 0.89 \\
& $(0.21)$ & $(0.29)$ & $(0.37)$ & $(0.48)$ & $(0.25)$ & $(0.34)$ \\
\hline County FE? & $\mathrm{Y}$ & $\mathrm{Y}$ & $\mathrm{Y}$ & $\mathrm{Y}$ & $\mathrm{Y}$ & $\mathrm{Y}$ \\
Calendar Time Controls? & $\mathrm{N}$ & $\mathrm{Y}$ & $\mathrm{N}$ & $\mathrm{Y}$ & $\mathrm{N}$ & $\mathrm{Y}$ \\
Econ Fundamentals? & $\mathrm{N}$ & $\mathrm{Y}$ & $\mathrm{N}$ & $\mathrm{Y}$ & $\mathrm{N}$ & $\mathrm{Y}$ \\
\hline No. County & 720 & 720 & 330 & 330 & 390 & 390 \\
\hline \hline
\end{tabular}

Note: The table presents coefficients from an event study regression of the change in mortgage financing features in a county relative to the timing of the estimated structural break in house prices. Estimates are the percentage point difference in each mortgage financing feature in year of the house price break relative to the previous year. Quadratic controls for calendar time used. Odd number columns show the results with no economic controls and even number columns show those with the economic controls, income level and unemployment rate. "Early" signifies counties with house price break prior to 2000. Standard errors clustered at the county level in parentheses. Source: Authors' calculations using HMDA, LPS Applied Analytics, Census, Bureau of Labor Statistics, and CoreLogic data. 
Table A.3: Credit Supply around First House Price Structural Breaks

\begin{tabular}{lccccccccc}
\hline \hline & & Overall & & & Early & & & Late \\
& $(1)$ & $(2)$ & $(3)$ & $(4)$ & $(5)$ & $(6)$ & $(7)$ & $(8)$ & $(9)$ \\
\hline \% Denied & -0.12 & 0.64 & 0.48 & 0.51 & 0.98 & 0.91 & -0.63 & 0.13 & 0.08 \\
& $(0.12)$ & $(0.16)$ & $(0.16)$ & $(0.18)$ & $(0.26)$ & $(0.26)$ & $(0.15)$ & $(0.20)$ & $(0.19)$ \\
\% Owner-occupied & -1.14 & -0.60 & -0.60 & -0.14 & 0.01 & 0.03 & -1.93 & -1.10 & -1.04 \\
& $(0.16)$ & $(0.18)$ & $(0.18)$ & $(0.30)$ & $(0.34)$ & $(0.34)$ & $(0.15)$ & $(0.18)$ & $(0.18)$ \\
1st Lien Loan-to-Value & -0.15 & -0.25 & -0.31 & 0.29 & -0.29 & -0.26 & -0.52 & -0.31 & -0.33 \\
& $(0.07)$ & $(0.09)$ & $(0.09)$ & $(0.13)$ & $(0.16)$ & $(0.16)$ & $(0.07)$ & $(0.09)$ & $(0.09)$ \\
Second Lien Share of All Originations & 0.81 & 0.49 & 0.51 & 0.05 & -0.25 & -0.28 & 1.43 & 1.14 & 1.10 \\
& $(0.05)$ & $(0.07)$ & $(0.07)$ & $(0.02)$ & $(0.03)$ & $(0.04)$ & $(0.09)$ & $(0.11)$ & $(0.11)$ \\
FICO & 0.37 & -0.61 & -0.48 & -0.06 & -0.26 & 0.07 & 0.60 & -1.04 & -0.80 \\
& $(0.46)$ & $(0.59)$ & $(0.59)$ & $(0.93)$ & $(1.20)$ & $(1.20)$ & $(0.37)$ & $(0.50)$ & $(0.50)$ \\
\% Full Documentation & -1.46 & -0.89 & -0.98 & -0.66 & 1.06 & 1.00 & -2.06 & -2.32 & -2.23 \\
& $(0.35)$ & $(0.43)$ & $(0.43)$ & $(0.65)$ & $(0.82)$ & $(0.83)$ & $(0.37)$ & $(0.45)$ & $(0.44)$ \\
\% Subprime & 2.06 & 1.17 & 1.25 & 1.38 & 0.32 & 0.24 & 2.64 & 2.00 & 1.94 \\
& $(0.13)$ & $(0.16)$ & $(0.17)$ & $(0.15)$ & $(0.18)$ & $(0.18)$ & $(0.19)$ & $(0.25)$ & $(0.25)$ \\
\% FHA & -1.29 & -1.09 & -1.06 & -0.08 & 0.09 & 0.17 & -2.24 & -2.05 & -1.91 \\
& $(0.12)$ & $(0.14)$ & $(0.14)$ & $(0.18)$ & $(0.22)$ & $(0.22)$ & $(0.16)$ & $(0.18)$ & $(0.17)$ \\
\hline County FE? & $\mathrm{Y}$ & $\mathrm{Y}$ & $\mathrm{Y}$ & $\mathrm{Y}$ & $\mathrm{Y}$ & $\mathrm{Y}$ & $\mathrm{Y}$ & $\mathrm{Y}$ & $\mathrm{Y}$ \\
Calendar Time Controls? & $\mathrm{N}$ & $\mathrm{Y}$ & $\mathrm{Y}$ & $\mathrm{N}$ & $\mathrm{Y}$ & $\mathrm{Y}$ & $\mathrm{N}$ & $\mathrm{Y}$ & $\mathrm{Y}$ \\
Econ Fundamentals? & $\mathrm{N}$ & $\mathrm{N}$ & $\mathrm{Y}$ & $\mathrm{N}$ & $\mathrm{N}$ & $\mathrm{Y}$ & $\mathrm{N}$ & $\mathrm{N}$ & $\mathrm{Y}$ \\
\hline \hline
\end{tabular}

Note: The table presents coefficients from an event study regression of the change in credit availability in a county relative to the timing of the first estimated structural break in house prices. Estimates are the percentage point difference in each mortgage financing feature in year of the house price break relative to the previous year. "Early" signifies counties with the first house price break prior to 2000. Robust standard errors in parentheses. Source: Authors' calculations using HMDA, LPS Applied Analytics, Bureau of Labor Statistics, and CoreLogic data. 
Table A.4: Economic Fundamentals around First House Price Breaks

\begin{tabular}{lcccccc}
\hline \hline & \multicolumn{2}{c}{ Overall } & \multicolumn{2}{c}{ Early } & \multicolumn{2}{c}{ Late } \\
& $(1)$ & $(2)$ & $(3)$ & $(4)$ & $(5)$ & $(6)$ \\
\hline Income (in 1000s) & 1.20 & 0.15 & 1.42 & 0.26 & 1.04 & 0.02 \\
& $(0.03)$ & $(0.03)$ & $(0.04)$ & $(0.05)$ & $(0.05)$ & $(0.05)$ \\
Unemployment & -0.24 & -0.19 & -0.40 & -0.10 & -0.13 & -0.22 \\
& $(0.02)$ & $(0.05)$ & $(0.03)$ & $(0.08)$ & $(0.03)$ & $(0.07)$ \\
\hline County FE? & $\mathrm{Y}$ & $\mathrm{Y}$ & $\mathrm{Y}$ & $\mathrm{Y}$ & $\mathrm{Y}$ & $\mathrm{Y}$ \\
Calendar Time Controls? & $\mathrm{N}$ & $\mathrm{Y}$ & $\mathrm{N}$ & $\mathrm{Y}$ & $\mathrm{N}$ & $\mathrm{Y}$ \\
\hline \hline
\end{tabular}

Note: The table presents coefficients from an event study regression of economic fundamentals in a county relative to the timing of the first estimated structural break in house prices. Estimates are the percentage point difference in each mortgage financing feature in year of the house price break relative to the previous year. "Early" signifies counties with the first house price break prior to 2000. Robust standard errors in parentheses. Source: Authors' calculations using HMDA, LPS Applied Analytics, Bureau of Labor Statistics, and CoreLogic data. 
Table A.5: Non-traditional Mortgages around House Price Structural Breaks

\begin{tabular}{lcccccc}
\hline \hline & \multicolumn{2}{c}{ 1st and/or 2nd Breaks } & \multicolumn{2}{c}{ 1st Break Only } & \multicolumn{2}{c}{ 2nd Break Only } \\
& $(1)$ & $(2)$ & $(3)$ & $(4)$ & $(5)$ & $(6)$ \\
\hline \% Any & 3.49 & 2.83 & 3.12 & 2.21 & 4.33 & 4.33 \\
& $(0.29)$ & $(0.32)$ & $(0.37)$ & $(0.40)$ & $(0.52)$ & $(0.60)$ \\
\% with Payment Gap & 2.84 & 1.82 & 2.62 & 1.41 & 3.36 & 2.78 \\
& $(0.20)$ & $(0.23)$ & $(0.25)$ & $(0.29)$ & $(0.33)$ & $(0.37)$ \\
\% Variable Rate & 3.09 & 2.65 & 2.81 & 2.10 & 3.73 & 3.96 \\
& $(0.29)$ & $(0.32)$ & $(0.37)$ & $(0.40)$ & $(0.53)$ & $(0.61)$ \\
\% Interest Only & 2.27 & 1.47 & 2.09 & 1.25 & 2.66 & 2.01 \\
& $(0.15)$ & $(0.15)$ & $(0.18)$ & $(0.18)$ & $(0.32)$ & $(0.31)$ \\
\% Extended Term & 0.13 & 0.09 & 0.07 & 0.04 & 0.28 & 0.20 \\
& $(0.02)$ & $(0.02)$ & $(0.02)$ & $(0.03)$ & $(0.04)$ & $(0.04)$ \\
\% Negative Amortization & 0.44 & 0.58 & 0.42 & 0.66 & 0.49 & 0.41 \\
& $(0.17)$ & $(0.23)$ & $(0.21)$ & $(0.29)$ & $(0.29)$ & $(0.37)$ \\
\hline County FE? & $\mathrm{Y}$ & $\mathrm{Y}$ & $\mathrm{Y}$ & $\mathrm{Y}$ & $\mathrm{Y}$ & $\mathrm{Y}$ \\
Calendar Time Controls? & $\mathrm{N}$ & $\mathrm{Y}$ & $\mathrm{N}$ & $\mathrm{Y}$ & $\mathrm{N}$ & $\mathrm{Y}$ \\
Econ Fundamentals? & $\mathrm{N}$ & $\mathrm{Y}$ & $\mathrm{N}$ & $\mathrm{Y}$ & $\mathrm{N}$ & $\mathrm{Y}$ \\
\hline No. County & 720 & 720 & 330 & 330 & 390 & 390 \\
\hline \hline
\end{tabular}

Note: The table presents coefficients from an event study regression of the change in mortgage financing features in a county relative to the timing of the estimated structural break in house prices. Estimates are the percentage point difference in each mortgage financing feature in year of the house price break relative to the previous year. Quadratic controls for calendar time used. Odd number columns show the results with no economic controls and even number columns show those with the economic controls, income level and unemployment rate. "Early" signifies counties with house price break prior to 2000. Standard errors clustered at the county level in parentheses. Source: Authors' calculations using HMDA, LPS Applied Analytics, Census, Bureau of Labor Statistics, and CoreLogic data. 
Table A.6: Credit Supply around House Price Structural Breaks

\begin{tabular}{lccccccccc}
\hline \hline & \multicolumn{3}{c}{ 1st and/or 2nd Breaks } & \multicolumn{3}{c}{ 1st Break Only } & \multicolumn{3}{c}{ 2nd Break Only } \\
& $(1)$ & $(2)$ & $(3)$ & $(4)$ & $(5)$ & $(6)$ & $(7)$ & $(8)$ & $(9)$ \\
\hline \% Denied & -0.02 & 0.77 & 0.59 & -0.12 & 0.64 & 0.48 & 0.20 & 1.05 & 0.81 \\
& $(0.09)$ & $(0.13)$ & $(0.13)$ & $(0.12)$ & $(0.16)$ & $(0.16)$ & $(0.15)$ & $(0.22)$ & $(0.22)$ \\
\% Owner-occupied & -1.04 & -0.56 & -0.56 & -1.14 & -0.60 & -0.60 & -0.81 & -0.49 & -0.50 \\
& $(0.13)$ & $(0.15)$ & $(0.15)$ & $(0.16)$ & $(0.18)$ & $(0.18)$ & $(0.23)$ & $(0.27)$ & $(0.27)$ \\
1st Lien Loan-to-Value & -0.04 & -0.17 & -0.22 & -0.15 & -0.25 & -0.31 & 0.20 & 0.01 & -0.04 \\
& $(0.06)$ & $(0.07)$ & $(0.07)$ & $(0.07)$ & $(0.09)$ & $(0.09)$ & $(0.09)$ & $(0.12)$ & $(0.12)$ \\
Second Lien Share of All Originations & 0.91 & 0.60 & 0.63 & 0.81 & 0.49 & 0.51 & 1.15 & 0.88 & 0.91 \\
& $(0.05)$ & $(0.06)$ & $(0.06)$ & $(0.05)$ & $(0.07)$ & $(0.07)$ & $(0.10)$ & $(0.13)$ & $(0.13)$ \\
FICO & -0.22 & -1.18 & -1.06 & 0.37 & -0.61 & -0.48 & -1.52 & -2.42 & -2.20 \\
& $(0.37)$ & $(0.47)$ & $(0.47)$ & $(0.46)$ & $(0.59)$ & $(0.59)$ & $(0.63)$ & $(0.71)$ & $(0.73)$ \\
\% Full Documentation & -1.11 & -0.82 & -0.92 & -1.46 & -0.89 & -0.98 & -0.37 & -0.68 & -0.79 \\
& $(0.28)$ & $(0.35)$ & $(0.35)$ & $(0.35)$ & $(0.43)$ & $(0.43)$ & $(0.46)$ & $(0.55)$ & $(0.55)$ \\
\% Subprime & 2.26 & 1.51 & 1.59 & 2.06 & 1.17 & 1.25 & 2.72 & 2.30 & 2.38 \\
& $(0.11)$ & $(0.14)$ & $(0.14)$ & $(0.13)$ & $(0.16)$ & $(0.17)$ & $(0.23)$ & $(0.29)$ & $(0.30)$ \\
\% FHA & -1.17 & -1.20 & -1.14 & -1.29 & -1.09 & -1.06 & -0.93 & -1.50 & -1.35 \\
& $(0.10)$ & $(0.11)$ & $(0.11)$ & $(0.12)$ & $(0.14)$ & $(0.14)$ & $(0.15)$ & $(0.18)$ & $(0.18)$ \\
\hline County FE? & $\mathrm{Y}$ & $\mathrm{Y}$ & $\mathrm{Y}$ & $\mathrm{Y}$ & $\mathrm{Y}$ & $\mathrm{Y}$ & $\mathrm{Y}$ & $\mathrm{Y}$ & $\mathrm{Y}$ \\
Calendar Time Controls? & $\mathrm{N}$ & $\mathrm{Y}$ & $\mathrm{Y}$ & $\mathrm{N}$ & $\mathrm{Y}$ & $\mathrm{Y}$ & $\mathrm{N}$ & $\mathrm{Y}$ & $\mathrm{Y}$ \\
Econ Fundamentals? & $\mathrm{N}$ & $\mathrm{N}$ & $\mathrm{Y}$ & $\mathrm{N}$ & $\mathrm{N}$ & $\mathrm{Y}$ & $\mathrm{N}$ & $\mathrm{N}$ & $\mathrm{Y}$ \\
\hline \hline
\end{tabular}

Note: The table presents coefficients from an event study regression of the change in credit availability and underwriting in a county relative to the timing of the estimated structural breaks in house prices. Estimates are the percentage point difference in each mortgage financing feature in year of the house price break relative to the previous year. Source: Authors' calculations using HMDA, LPS Applied Analytics, Bureau of Labor Statistics, and CoreLogic data. 
Table A.7: Breaks in Non-traditional Mortgages relative to House Price Breaks

(a) First House Price Break

\begin{tabular}{|c|c|c|c|c|}
\hline & \multicolumn{3}{|c|}{ With Respect to House Price Break } & \multirow{2}{*}{$\begin{array}{c}\text { Share } \\
\text { Estimated } \\
(4)\end{array}$} \\
\hline & $\begin{array}{c}\text { Before } \\
\text { (1) }\end{array}$ & $\begin{array}{l}\text { Same } \\
(2)\end{array}$ & $\begin{array}{c}\text { After } \\
\text { (3) }\end{array}$ & \\
\hline Any Break & 9.55 & 1.63 & 26.93 & 38.11 \\
\hline Payment Gap Break & 11.28 & 2.64 & 15.96 & 29.88 \\
\hline Variable Rate Break & 9.35 & 1.32 & 25.00 & 35.67 \\
\hline Interest Only Break & 9.65 & 6.00 & 57.22 & 72.87 \\
\hline Extended Term Break & 4.57 & 0.81 & 44.92 & 50.30 \\
\hline Negative Amortization Break & 19.72 & 0.61 & 20.73 & 41.06 \\
\hline
\end{tabular}

(b) Second House Price Break

\begin{tabular}{lcccc}
\hline \hline & \multicolumn{2}{c}{ With Respect to House Price Break } & Share \\
\cline { 2 - 4 } & $\begin{array}{c}\text { Before } \\
\text { Estimated }\end{array}$ & $\begin{array}{c}\text { Same } \\
(1)\end{array}$ & $\begin{array}{c}\text { After } \\
(2)\end{array}$ & $\begin{array}{c}\text { (3) } \\
(4)\end{array}$ \\
\hline Any Break & 16.81 & 1.99 & 11.95 & 30.75 \\
Payment Gap Break & 15.93 & 1.33 & 7.52 & 24.78 \\
Variable Rate Break & 15.71 & 1.99 & 11.5 & 29.20 \\
Interest Only Break & 19.91 & 9.73 & 40.49 & 70.13 \\
Extended Term Break & 7.52 & 1.55 & 35.84 & 44.91 \\
Negative Amortization Break & 22.57 & 0.66 & 21.02 & 44.25 \\
\hline \hline
\end{tabular}

Note: The tables show whether structural breaks in non-traditional mortgage variables occur before, concurrently, or after first or second estimated structural breaks in house prices in a given county. The break is defined to occur "before" if (difference) $<3$, "concurrently" if $-3<$ (difference) $<3$, and "after" if (difference) $>3$. First three columns do not necessarily sum to 100 percent in a given row because counties do not always have an estimated break in other variables. Sample consists of counties experiencing each house price break. Source: Authors' calculations using HMDA, LPS Applied Analytics, Bureau of Labor Statistics, and CoreLogic data. 
Table A.8: House Price Growth around Breaks using Alternative Specifications

(a) First House Price Break

\begin{tabular}{lcccccc}
\hline \hline & \multicolumn{2}{c}{ Overall } & \multicolumn{2}{c}{ Pre-2000 } & \multicolumn{2}{c}{ Post-2000 } \\
& $(1)$ & $(2)$ & $(3)$ & $(4)$ & $(5)$ & $(6)$ \\
\hline House Price Growth & 7.12 & 6.93 & 6.23 & 5.53 & 7.84 & 7.99 \\
& $(0.13)$ & $(0.15)$ & $(0.17)$ & $(0.18)$ & $(0.18)$ & $(0.21)$ \\
\hline County FE? & $\mathrm{Y}$ & $\mathrm{Y}$ & $\mathrm{Y}$ & $\mathrm{Y}$ & $\mathrm{Y}$ & $\mathrm{Y}$ \\
Calendar Time Controls? & $\mathrm{N}$ & $\mathrm{Y}$ & $\mathrm{N}$ & $\mathrm{Y}$ & $\mathrm{N}$ & $\mathrm{Y}$ \\
Econ Fundamentals? & $\mathrm{N}$ & $\mathrm{Y}$ & $\mathrm{N}$ & $\mathrm{Y}$ & $\mathrm{N}$ & $\mathrm{Y}$ \\
\hline Within R-sq. & 0.25 & 0.28 & 0.33 & 0.39 & 0.26 & 0.36 \\
No. Obs & 92092 & 92092 & 39419 & 39419 & 52673 & 52673 \\
No. County & 984 & 984 & 434 & 434 & 550 & 550 \\
\hline \hline
\end{tabular}

(b) Second House Price Break

\begin{tabular}{lcccccc}
\hline \hline & \multicolumn{2}{c}{ Overall } & \multicolumn{2}{c}{ Pre-2000 } & \multicolumn{2}{c}{ Post-2000 } \\
& $(1)$ & $(2)$ & $(3)$ & $(4)$ & $(5)$ & $(6)$ \\
\hline House Price Growth & 3.91 & 4.68 & 3.93 & 4.04 & 3.91 & 4.87 \\
& $(0.16)$ & $(0.17)$ & $(0.29)$ & $(0.31)$ & $(0.19)$ & $(0.21)$ \\
\hline County FE? & $\mathrm{Y}$ & $\mathrm{Y}$ & $\mathrm{Y}$ & $\mathrm{Y}$ & $\mathrm{Y}$ & $\mathrm{Y}$ \\
Calendar Time Controls? & $\mathrm{N}$ & $\mathrm{Y}$ & $\mathrm{N}$ & $\mathrm{Y}$ & $\mathrm{N}$ & $\mathrm{Y}$ \\
Econ Fundamentals? & $\mathrm{N}$ & $\mathrm{Y}$ & $\mathrm{N}$ & $\mathrm{Y}$ & $\mathrm{N}$ & $\mathrm{Y}$ \\
\hline Within R-sq. & 0.21 & 0.29 & 0.11 & 0.14 & 0.26 & 0.34 \\
No. Obs & 42790 & 42790 & 10214 & 10214 & 32576 & 32576 \\
No. County & 452 & 452 & 111 & 111 & 341 & 341 \\
\hline \hline
\end{tabular}

(c) First and/or Second House Price Break

\begin{tabular}{lcccccc}
\hline \hline & \multicolumn{2}{c}{ Overall } & \multicolumn{2}{c}{ Pre-2000 } & \multicolumn{2}{c}{ Post-2000 } \\
& $(1)$ & $(2)$ & $(3)$ & $(4)$ & $(5)$ & $(6)$ \\
\hline House Price Growth & 6.11 & 6.19 & 5.75 & 5.19 & 6.33 & 6.77 \\
& $(0.11)$ & $(0.12)$ & $(0.15)$ & $(0.16)$ & $(0.15)$ & $(0.16)$ \\
\hline County FE? & $\mathrm{Y}$ & $\mathrm{Y}$ & $\mathrm{Y}$ & $\mathrm{Y}$ & $\mathrm{Y}$ & $\mathrm{Y}$ \\
Calendar Time Controls? & $\mathrm{N}$ & $\mathrm{Y}$ & $\mathrm{N}$ & $\mathrm{Y}$ & $\mathrm{N}$ & $\mathrm{Y}$ \\
Econ Fundamentals? & $\mathrm{N}$ & $\mathrm{Y}$ & $\mathrm{N}$ & $\mathrm{Y}$ & $\mathrm{N}$ & $\mathrm{Y}$ \\
\hline Within R-sq. & 0.16 & 0.23 & 0.25 & 0.31 & 0.19 & 0.30 \\
No. Obs & 134882 & 134882 & 49633 & 49633 & 85249 & 85249 \\
No. County & 1106 & 1106 & 510 & 510 & 792 & 792 \\
\hline \hline
\end{tabular}

Note: This set of tables uses an alternative specification of pre-2000 vs. post-2000 breaks. The previous Table 1 (A) only considers whether each county's first break is before $2000 \mathrm{~m} 1$ or after $2000 \mathrm{~m} 1$, and this was problematic for some counties that only have second breaks but no first breaks. Alternatively, Table 1(B) here considers whether each break is before or after $2000 \mathrm{~m} 1$. 
Table A.9: Changes in House Prices and Alternative Financing, by Non-Core Lending (NCL) Quartile

\begin{tabular}{lccccccc}
\hline \hline & Value of variable & \multicolumn{7}{c}{ Coef on Q4*event time } & & \\
& for Q1 July 2003 & July 2002 & July 2003 & July 2004 & July 2005 & July 2006 & $\mathrm{N}$ \\
\hline House Price Growth & 4.97 & -0.9 & 0 & 0.74 & 3.78 & 2.72 & 111,552 \\
& $(0.33)$ & $(0.29)$ & $(0)$ & $(0.31)$ & $(0.49)$ & $(0.57)$ & \\
Any Alternative & 16.90 & -0.58 & 0 & 7.31 & 14.28 & 13.68 & 111,285 \\
& $(0.89)$ & $(0.54)$ & $(0)$ & $(0.62)$ & $(0.89)$ & $(0.89)$ & \\
Payment Gap & 11.67 & -0.51 & 0 & 4.43 & 8.11 & 8.09 & 81,974 \\
& $(1.10)$ & $(0.33)$ & $(0)$ & $(0.48)$ & $(0.69)$ & $(0.76)$ & \\
Variable Rate & 13.31 & -1.69 & 0 & 6.70 & 12.81 & 12.46 & 81,974 \\
& $(1.23)$ & $(0.34)$ & $(0)$ & $(0.50)$ & $(0.86)$ & $(0.90)$ & \\
Interest Only & 0.70 & -1.26 & 0 & 5.72 & 15.11 & 16.82 & 81,973 \\
& $(0.14)$ & $(0.15)$ & $(0)$ & $(0.42)$ & $(0.91)$ & $(0.96)$ & \\
Extended Term & 0.09 & -0.09 & 0 & -0.01 & 0.35 & 2.09 & 81,974 \\
& $(0.04)$ & $(0.06)$ & $(0)$ & $(0.02)$ & $(0.05)$ & $(0.18)$ & \\
Negative Amortization & 9.03 & -0.45 & 0 & 0.84 & 2.70 & 4.35 & 80,236 \\
& $(1.20)$ & $(0.61)$ & $(0)$ & $(0.47)$ & $(0.59)$ & $(0.63)$ & \\
\hline \hline
\end{tabular}

Note: This table presents regression coefficient estimates from the event study implied by Figure 13 comparing the difference between the top and bottom quartiles of counties with relatively more or less exposure to the secondary securitization market (as proxied by share of non-core deposits). The time series are centered around zero in July 2003. Standard errors, clustered by county, are in parentheses. See text for details. 
Table A.10: Changes in Mortgage Attributes, by Non-Core Lending (NCL) Quartile

\begin{tabular}{lccccccc}
\hline \hline & Value of variable & \multicolumn{7}{c}{ Coef on Q4*event time (year from event) } & \\
& for Q1 July 2003 & July 2002 & July 2003 & July 2004 & July 2005 & July 2006 & $\mathrm{N}$ \\
\hline Denial Rate & 13.41 & -1.63 & 0 & 0.15 & 0.66 & 2.05 & 100,506 \\
& $(1.71)$ & $(0.25)$ & $(0)$ & $(0.19)$ & $(0.23)$ & $(0.28)$ & \\
Owner Occupied & 85.61 & 0.36 & 0 & -0.48 & -1.69 & -2.32 & 100,506 \\
& $(0.70)$ & $(0.22)$ & $(0)$ & $(0.24)$ & $(0.35)$ & $(0.40)$ & \\
LTV Ratio & 84.31 & 0.37 & 0 & -0.41 & -0.26 & -0.21 & 81,974 \\
& $(0.42)$ & $(0.15)$ & $(0)$ & $(0.12)$ & $(0.18)$ & $(0.21)$ & \\
Second Lien & 7.23 & 0.44 & 0 & 2.42 & 6.17 & 8.21 & 111,517 \\
\multirow{5}{*}{ FICO } & $(0.67)$ & $(0.16)$ & $(0)$ & $(0.19)$ & $(0.36)$ & $(0.42)$ & \\
& 699.31 & 1.12 & 0 & 3.59 & 5.24 & 7.11 & 81,971 \\
Full Doc & $(2.23)$ & $(0.64)$ & $(0)$ & $(0.51)$ & $(0.62)$ & $(0.72)$ & \\
\multirow{4}{*}{ Subprime Share } & 69.28 & -1.53 & 0 & -1.98 & -3.39 & -8.31 & 81,398 \\
& $(1.11)$ & $(0.85)$ & $(0)$ & $(0.62)$ & $(0.80)$ & $(1.01)$ & \\
FHA & 4.95 & -0.94 & 0 & 1.72 & 2.84 & 2.51 & 111,514 \\
& $(1.41)$ & $(0.18)$ & $(0)$ & $(0.20)$ & $(0.31)$ & $(0.32)$ & \\
& 11.92 & 1.46 & 0 & -1.88 & -3.86 & -5.15 & 100,506 \\
\hline \hline
\end{tabular}

Note: This table presents regression coefficient estimates from the event study implied by Figure 14 comparing the difference between the top and bottom quartiles of counties with relatively more or less exposure to the secondary securitization market (as proxied by share of non-core deposits). The time series are centered around zero in July 2003. Standard errors, clustered by county, are in parentheses. See text for details. 